\title{
Identity and Redistribution*
}

\author{
Erik Lindqvist ${ }^{\dagger} \quad$ Robert Östling ${ }^{\ddagger}$ \\ SSE/EFI Working Paper Series in Economics and Finance No 659 \\ August 28, 2009
}

\begin{abstract}
This paper models the interaction between individuals' identity choices and redistribution. Both redistributive policies and identity choices are endogenous, and there might be multiple equilibria. The model is applied to ethnicity and social class. In an equilibrium with high taxes, the poor identify as poor and favor high taxes. In an equilibrium with low taxes, at least some of the poor identify with their ethnic group and favor low taxes. The model has two main predictions. First, redistribution is highest when society is ethnically homogenous, but the effect of ethnic diversity on redistribution is not necessarily monotonic. Second, when income inequality is low, an increase in income inequality might induce the poor to identify with their ethnic group and therefore favor lower taxes.
\end{abstract}

Keywords: Redistribution, social identity, income inequality, ethnic fractionalization, ethnic diversity, social class.

JEL codes: H20, J15.

*Previous versions of this paper have been published in the authors' dissertations, Lindqvist (2007) and Östling (2008). We would like to thank Alberto Alesina, Johan Almenberg, George Baker, Kaushik Basu, Milo Bianchi, Tore Ellingsen, Ola Granström, Magnus Johannesson, Botond Kőszegi, Glenn C. Loury, Erik Mohlin, Ola Olsson, Torsten Persson, Daniel N. Posner, Per Sonnerby, Björn Tyrefors, Björn Wallace and seminar participants at the EEA Congress 2006, Massachusetts Institute of Technology, Stockholm School of Economics and the Zeuthen Workshop on Behavioral Economics 2005 for valuable comments. Financial support from the Jan Wallander and Tom Hedelius Foundation is gratefully acknowledged.

${ }^{\dagger}$ Research Institute of Industrial Economics, P.O. Box 55665, SE-102 15 Stockholm, Sweden. E-mail: erik.lindqvist@ifn.se.

${ }^{\ddagger}$ Institute for International Economic Studies, Stockholm University, SE-106 91 Stockholm, Sweden. E-mail: robert.ostling@iies.su.se. 


\section{Introduction}

The Marxian solidarity between the toilers of all the earth will, indeed, have a long way to go as far as concerns solidarity of the poor white Americans with the toiling Negro. (Myrdal 1944, p. 69)

Both the canonical economic theory of redistribution (e.g. Meltzer and Richard 1981) and Marxian theory assume that people's political preferences are determined by their economic position in society. This view is controversial. Conflicts along other dimensions, such as ethnicity, race, religion or gender, may be more important than social class. In particular, it has often been argued that class conflict is rare in societies that are ethnically divided. For example, the racial diversity among the American working class is a recurring theme in the literature on the failure to establish a strong worker's movement in the United States. ${ }^{1}$

The view that there are multiple dimensions of political conflict provokes the question under what circumstances there is salient political conflict along a particular dimension. This question has previously been addressed from a "political supply-side" perspective, i.e., why politicians may want to bundle policies on economic and non-economic issues for given voter preferences (e.g., Roemer 1998, Lee and Roemer 2006 and Roemer and van der Straeten 2005, 2006). In this paper, we focus on the complementary "demand-side" question about the determinants of voter preferences for redistribution.

In-group favoritism is a well-documented fact (e.g., Bernhard et al. 2006, Goette et al. 2006 and Efferson et al. 2008) and a potentially important determinant of preferences for redistribution..$^{2}$ For example, a poor person in a relatively rich ethnic minority group is likely to prefer more redistribution if she primarily sees herself as belonging to the working class rather than her ethnic group. In this paper, we view identity as altruism directed toward a specific group and study the determinants and consequences of voters' identity choices. $^{3}$ Our formal framework is based on the work of Shayo (2009) and allows both redistribution and identity choices to be determined endogenously. We use ethnicity and social class as our leading example throughout the paper, but the model is applicable to any situation where there are two potential dimensions of social cleavage. ${ }^{4}$

\footnotetext{
${ }^{1}$ See, for example, Myrdal (1944), Glazer and Moynihan (1970) and Lipset and Marks (2000).

${ }^{2}$ Furthermore, ethnicity and class are often significant predictors of preferences for redistribution. For example, see Fong (2001), Alesina et al. (2001) and Alesina and La Ferrara (2005b) for evidence that white people in the US are more negative toward redistribution than African-Americans also when personal income is held constant.

${ }^{3}$ See Charness et al. (2007) and Chen and Li (2009) for recent empirical evidence that individuals are altruistic toward the group they identify with.

${ }^{4}$ See Posner (2005) for a variety of different examples of two-dimensional social cleavages, and Alesina
} 
In the model, identity choices are determined by two factors. First, individuals tend to identify with groups that have high status, which in the model is equivalent to a high aftertax income. This assumption is motivated by a large body of empirical research in social psychology (see Roccas 2003 for a survey). Second, people tend to identify with groups that are similar to themselves. This assumption is consistent both with self-categorization theory in social psychology (Turner et al. 1987) and with evolutionary theory.

Incorporating endogenous identity choices into a standard model of redistribution (e.g. Meltzer and Richard 1981) profoundly changes the predictions. In the standard model, changes in the distribution of income and composition of ethnic groups only affect the level of redistribution by changing the median relative to the average income in the population. In our model, however, such changes also affect the level of redistribution by shifting the identity choices of members in different ethnic groups.

Most importantly, the model yields novel insights regarding the effect of ethnic diversity on redistribution. On the one hand, increasing the size of an ethnic group makes class identification more attractive for members of this ethnic group because it now constitutes a large fraction of each social class. This implies that the poor in the ethnic group may start to identify with their social class and support higher levels of redistribution. On the other hand, increasing the size of one ethnic group implies that class identification becomes less attractive for other ethnic groups since these groups now constitute a smaller fraction of each social class.

For example, consider the simplest possible case when there is only two social classes (rich and poor) and two ethnic groups (black and white). In this case, poor whites are most prone to identify as poor and favor high taxes when there are no blacks in society at all. As the number of poor blacks increases, the perceived similarity with the poor group decreases, implying that poor whites might switch to a white identity. Since whites are on average richer than the poor, poor whites will favor lower taxes if they primarily identify themselves as white. This mechanism can explain why social class seems to be more important, and redistribution higher, in ethnically more homogeneous societies (e.g. Scandinavia compared to the US). However, for poor blacks, an increase in the proportion of blacks implies that they become more similar to the poor group. Consequently, an increase in the number of blacks might induce poor blacks to identify with the poor and favor more redistribution. The effect of ethnic diversity on redistribution is therefore not necessarily monotonic in our model.

The endogeneity of identity choices also changes the relationship between pre-tax income inequality and redistribution. In the model, an increase in pre-tax income inequality

and La Ferrara (2005a) for further motivation why ethnic identitification is likely to be endogenous to economic policy. 
from a low level increases after-tax income differences and hence the status difference between ethnic and poor identities. This implies that the poor become more likely to identify with their ethnic group and favor low taxes. Higher pre-tax income inequality might consequently lead to less redistribution. This is in accordance with empirical evidence (e.g. Perotti 1996 and Lind 2005) but contrasts with the standard model of redistribution (e.g. Meltzer and Richard 1981).

The model also allows us to study more complicated interactions beween income inequality, ethnic diversity and redistribution, such as the of effect of increasing the number of poor in a minority group and changes in income differences across ethnic groups.

A feature of the model is that there is a complementarity between tax rates and identity choices. A higher tax rate increases the after-tax income of the poor group more than the income of the ethnic groups. This increases the status of the poor identity relative to ethnic identities and makes it more likely that the poor identify with their social class and prefer higher taxes. The complementarity between tax rates and identity choices implies that there might be multiple equilibria. For example, we may have one high tax equilibrium where the poor identify as poor and one low tax equilibrium where they identify with their respective ethnic group. ${ }^{5}$

Our approach differs from previous economic theories of ethnic diversity and redistributive policies. ${ }^{6}$ First, there are models that expand the policy space with a non-economic issue or targeted transfers. Roemer (1998), Lee and Roemer (2006) and Roemer and van der Straeten $(2005,2006)$ study how an additional non-economic political issue such as religion or race leads to a bundling effect of political policies. ${ }^{7}$ A citizen that favors a high degree of redistribution may vote for a political party that advocates a low degree of redistribution if he favors the political party's position on racial issues. Building on Levy (2004), Fernández and Levy (2008) instead consider endogenous political parties where the policy space consists of general redistribution and targeted public goods. For intermediate levels of preference diversity they find that the rich might form a winning coalition with special interest groups among the poor to reduce general redistribution. A second type of

\footnotetext{
${ }^{5}$ The presence of multiple equilibria suggests that the model may be difficult to test empirically. However, the formally stated results provide predictions given initial identity choices, incomes and population proportions of different groups. Income and population proportions are easily available data, and there are several ways to empirically measure people's identities, for example using survey responses or the probability of homogamy (see Bisin et al. 2006 for a recent example). Given such data, our model provides empirically testable predictions for both the level of redistribution and individuals' identity choices.

${ }^{6}$ More generally, ethnic heterogeneity might of course also influence economic outcomes through other channels than the political system. For example, ethnicity might influence the ease by which people cooperate, act as focal points in coordination games or affect the possibility to enforce social forms through social networks. See Habyarimana et al. (2007) for references and an overview of this literature.

${ }^{7}$ Austen-Smith and Wallerstein (2006) develop a related model of legislative bargaining. See also CondeRuiz and Galasso (2003) for a model of bidimensional voting in a different context.
} 
explanation, put forward by, e.g., Alesina et al. (1999) and Alesina et al. (2001), concerns a direct effect of ethnic fragmentation on voter preferences for redistribution. In these authors' view, a voter's altruistic motive for redistribution is confined to people that belong to her own ethnic group. Common to both types of explanations is that voters' political preferences on ethnic issues are exogenous, whereas both preferences and redistribution are determined endogenously in our model.

This paper is most closely related to Shayo (2009). ${ }^{8}$ He develops a general theoretical framework of social identification and applies it to a model of redistribution where individuals have a choice between identifying with their social class (rich or poor) and a common nationalist identity. We apply a similar model of redistribution to the study of ethnic identification and introduce heterogeneity along two dimensions, i.e., both income and ethnicity. This allows us to explicitly study the effects of changes in the demographic composition of society, such as changes in ethnic diversity, interethnic income inequality and the immigration of low-skilled immigrants. Heterogeneity along two dimensions also implies that more than one group can influence the tax rate, creating an interdependence between the identity choices of different groups.

In the next section of the paper, we develop the model with arbitrarily many ethnic groups and social classes. We show that in this general setting, but with restrictive assumptions on the income distribution, increasing the size of a small ethnic group, or adding a small ethnic group to the population, might reduce the level of redistribution. This is in line with the empirical finding that ethnic diversity is associated with lower levels of redistribution (see Alesina and La Ferrara 2005 for a survey of this literature). In Section 3 we outline the more tractable case when there are only two social classes (rich and poor) and two ethnic groups (black and white), which allows us to derive the richer set of predictions presented in Section 4 and 5. Section 4 and 5 provide formal results when ethnic groups are equally rich as well as a verbal account of the case when there are income differences across ethnic groups. The formal results when there is interethnic income inequality are available in Appendix B. Section 6 discusses how social mobility can be analyzed in our model. The final section discusses "American Exceptionalism" - the difference in redistribution between the United States and Western Europe - in the context of our model.

\section{General Model}

Consider a set of $N$ agents, a finite set $C$ of social classes and a finite set $E$ of ethnic groups. The model could equally well be applied to identities along two other dimensions, for example language and religion, but we focus on class and ethnicity in the remainder of the

\footnotetext{
${ }^{8}$ See Penn (2008) for another application of Shayo's framework.
} 
paper. Social classes partitions the income distribution and each social class corresponds to a particular interval of the income distribution, i.e., all agents within a certain income interval belongs to the social class corresponding to that interval. ${ }^{9}$ Each agent also belongs to one ethnic group. ${ }^{10}$ All social classes are represented in every ethnic group, and we refer to a particular combination of class and ethnicity as a type. Agents must choose to identify with either their ethnic group or their social class. ${ }^{11}$ Given this identity choice, agents also choose which tax rate to vote for. In equilibrium we require that the resulting median tax rate is consistent with identity and voting choices.

Each agent in the economy is endowed with pre-tax income $y_{i}>0$ and the average income in the population is denoted by $y$. There is a single proportional tax rate $t$ and tax revenues are redistributed lump-sum. ${ }^{12}$ There is a quadratic deadweight loss of taxation equal to $\left(t^{2} / 2\right) y{ }^{13}$ This implies that that the income after taxes and transfers of agent $i$ is $\bar{y}_{i}=(1-t) y_{i}+\left(t-t^{2} / 2\right) y$. Similarly, let $y_{j}$ denote the average pre-tax income of the agents belonging to ethnic group $j \in E$ or social class $j \in C$ so that their average after-tax income (including transfers) is given by $\bar{y}_{j}=(1-t) y_{j}+\left(t-t^{2} / 2\right) y$.

Since each agent belongs to one social class and one ethnic group, the average income of these two categories will generally differ. For an agent with low income, the average

\footnotetext{
${ }^{9}$ It is not necessary to define social classes in terms of income intervals. One can think of more complicated mappings that takes educational and cultural aspects into account. Proposition 1 holds also with such alternative interpretations.

${ }^{10} \mathrm{We}$ assume that there is an uncontroversial way to determine which ethnic group each agent in the economy belongs to. In practice, this is of course easier said than done. For an axiomatic approach to determination of group membership, see Kasher and Rubinstein (1997).

${ }^{11}$ The assumption that agents must either identify with their class or ethnicity raises three different issues. First, agents are not allowed to identify with their type, i.e., their particular combination of class and ethnicity. This assumption may seem restrictive, but we believe it captures an important aspect of the identity concept: that an identity is both exclusive ("I am different from people with whom I do not share characteristic X") and inclusive ("I am similar to those with whom I share characteristic X"). To capture the notion that identy is inclusive (and not only exclusive) in the case where agents only differ along two dimensions, we cannot allow people to identify with their specific type. In addition, a model where agents could identify with their particular type would come very close to the standard model of redistribution. Second, why can an individual not identify with both her ethnic group and her social class? In this setting, an agent "cannot have both" since she has to vote for her preferred level of redistribution which forces her to decide on how much to favor either of her two groups. However, it is straightforward to allow for intermediate identification, e.g. 30 percent class identification and 70 percent ethnic identification (see footnote 14). Third, we do not allow agents to identify with a group they do not belong to. Though we could allow agents to identify with any group in society, this aspect is not relevant in contexts where it is very costly to shift ethnic identity (for example, from black to white in the US).

${ }^{12}$ There are two main reasons why we focus on general redistribution (i.e., from rich to poor) and do not allow targeted redistribution. First, the empirical literature concerning ethnic diversity and redistribution mainly concerns general redistribution. Second, many democracies have high legal barriers to discriminatory redistributive policies which limits the scope for redistribution targeted to specific ethnic groups. In a more general model, barriers to targeted redistribution might be endogenously determined, but we have left this question for future research.

${ }^{13}$ The results in this section of the paper holds as long as the deadweight loss is strictly convex in $t$ so that unique solutions to agents' voting problems exist and preferences are single-peaked.
} 
income in her ethnic group will typically be higher than in her social class, whereas for rich people the social class will typically have a higher average income than the ethnic group. We refer to the category with the higher pre-tax income as the agent's high status identity and the other as the low status identity. The average pre-tax income in the high status versus low status identity is denoted by $y_{H}$ and $y_{L}$ where $y_{H} \geq y_{L}$. The identity choice consists of choosing $l_{i}$ to be either zero or one, where $l_{i}=1$ means that the agent identifies with the low status group and $l_{i}=0$ that she identifies with her high status group. ${ }^{14}$

An agent's utility consists of two parts: material utility arising from after-tax income including transfers and the immaterial utility arising from identification with a group. Immaterial utility from group identification in turn consists of the status of the group and the perceived similarity with the other members of the group. Group status is linearly increasing in the group's after-tax average income. We focus on after-tax (instead of pretax) income differences because consumption is a more credible signal of economic status than pre-tax income. While many forms of consumption, like housing, cars or clothes, are directly visible markers of economic status, tax records are not public information in most countries. ${ }^{15}$ We assume that people tend to identify with groups with high status, which is well-documented in empirical research (see Roccas 2003 for a survey).

The utility function is assumed to be additively separable and take the following form:

$$
U_{i}=\bar{y}_{i}(t)+l_{i}\left[\gamma \bar{y}_{L}(t)-\delta d_{L}\right]+\left(1-l_{i}\right)\left[\gamma \bar{y}_{H}(t)-\delta d_{H}\right]
$$

where $t$ is the prevailing tax rate, $\bar{y}_{H}(t)$ and $\bar{y}_{L}(t)$ are the after-tax incomes of the two categories the agent belongs to and $d_{L}$ and $d_{H}$ the corresponding distances to (or dissimilarity with) each group. The first term in the utility function represents direct material benefit of after-tax income, the second term the immaterial utility when identifying with the low status group and the last term the immaterial utility when identifying with the high status group. The parameters $\gamma$ and $\delta$ are positive so that utility is increasing in status and decreasing in perceived distance.

The distances to a group is higher the larger is the share of people of a different type than oneself in the group. Based on research in social psychology, the tendency to identify with groups that are perceived to be similar to oneself can be viewed as a cognitive process of self-categorization and our measure of dissimilarity can be seen as distances in a conceptual space (see Shayo 2009 for further discussion). However, it may also reflect

\footnotetext{
${ }^{14}$ We assume that an agent cannot partially identify with a group. However, Proposition 1 is unaffected if the agent is allowed to pick $l_{i} \in[0,1]$ as long as the specification implies a unique solution $l_{i}^{*}(t)$ that is non-decreasing in $t$.

${ }^{15}$ Note, however, that it is not critical that status only depends on after-tax income. Status may also depend on other exogenous factors, such as pre-tax income and occupation, which could be incorporated into the model without qualitatively changing our results.
} 
a more automated and affective process. People tend to be more altruistic toward kin than nonkin, but, as argued by for example Waldman (1987), the recognition of kin is not perfect and relies on a variety of proximate mechanisms. Similarity in terms of ethnicity or social standing may thus function as perceptual cues that trigger altruistic behavior even when actual kinship bonds are weak.

In order to define the distance functions more precisely, let $p_{j k}$ denote the proportion in the population that belong to social class $j \in C$ and ethnic group $k \in E$. The distance of an agent that belongs to social class $j$ and ethnic group $k$ to his social class $j$ is given by

$$
d_{j k j}=d\left(\beta \sum_{h \in E \backslash\{k\}} p_{j h} / \sum_{h \in E} p_{j h}\right),
$$

where $d(\cdot)$ is some positive and increasing real-valued function and $\beta>0$. In other words, the distance to the class identity is increasing in the proportion of people belonging to the same social class that is from a different ethnic group. The parameter $\beta$ is a measure of ethnic tensions - if $\beta$ is high, the distance to the class identity is large since the members of a social class come from different ethnic groups.

Similarly, an agent that belongs to social class $j$ and ethnic group $k$ has the following distance to his ethnic group $k$ :

$$
d_{j k k}=d\left(\alpha \sum_{h \in C \backslash\{j\}} p_{h k} / \sum_{h \in C} p_{h k}\right),
$$

where $\alpha>0$ is a measure of class tensions. Note that perceived distances do not depend on tax rates - the tax rate only affects the material utility and the relative status of groups.

The above specification implies that the distance to an identity is unaffected by the identity choices of other agents - the distance to a certain identity only depends on characteristics of the population. ${ }^{16}$

The tax rate $t$ is determined by a political process that selects the median tax under the assumption of single-peaked preferences, for example Downsian electoral competition with two office-motivated candidates. The political process will hence be a mapping $\Gamma$ from the vector of all tax votes $t^{*} \in \times_{i \in N}[0,1]$ to a median tax rate $t \in[0,1]$.

We require that the following three conditions must hold in equilibrium:

1. All agents choose identity optimally given the prevailing tax rate $t$ :

$$
l_{i}^{*}(t)=\underset{l_{i} \in\{0,1\}}{\arg \max }\left\{\bar{y}_{i}(t)+l_{i}\left[\gamma \bar{y}_{L}(t)-\delta d_{L}\right]+\left(1-l_{i}\right)\left[\gamma \bar{y}_{H}(t)-\delta d_{H}\right]\right\} .
$$

\footnotetext{
${ }^{16}$ This assumption implies that people's identity choices are not affected by how they are perceived by others, e.g., whether other people view them as primarily "black" or "poor". Such concerns could, however, be incorporated in our model by the ethnic and class distance parameters $(\beta$ and $\alpha)$.
} 
2. All individuals vote for their preferred tax rate given the identity choice $l_{i}$ :

$$
t_{i}^{*}\left(l_{i}\right)=\underset{t \in[0,1]}{\arg \max }\left\{\bar{y}_{i}(t)+l_{i}\left[\gamma \bar{y}_{L}(t)-\delta d_{L}\right]+\left(1-l_{i}\right)\left[\gamma \bar{y}_{H}(t)-\delta d_{H}\right]\right\}
$$

3. The median tax rate is consistent with identity choices and voting behavior of all individuals:

$$
\Gamma\left(t^{*}\left(l^{*}(t)\right)\right)=t
$$

Note that identity and voting choices are taken separately. The main reason for this assumption is that these are two conceptually different decisions that are likely to be made under different circumstances and at different points in time. The equilibrium concept is aimed to capture the steady state of a dynamic process where people vote for taxes given their identity choices, but may change their identity choice as a new tax rate is implemented. ${ }^{17}$ A second reason is that preferences for taxes are single-peaked only for given identity choices. In order to be able to use the median voter theorem we cannot admit agents to switch identity at the same time as they choose tax rates.

First consider the agents' voting choices. The utility function (1) is strictly concave in $t$ and we can therefore use the first-order condition to derive the solution to the agent's tax voting decision:

$$
t_{i}^{*}\left(l_{i}\right)=\max \left\{1-\frac{y_{i}+\gamma\left(l_{i} y_{L}+\left(1-l_{i}\right) y_{H}\right)}{(1+\gamma) y}, 0\right\} .
$$

Note that this tax rate is non-decreasing in $l_{i}$, i.e., the more the agent identifies with the low status identity, the higher is her preferred tax. The reason is that people are altruistic toward the group they identify with. Since the low status group is poorer, an agent favors more redistribution if she identifies with that group. That people tend vote for tax rates in this way is shown in an experiment by Klor and Shayo (2009).

Now consider optimal identity choices. For a given tax rate $t$, an agent chooses the high status identity, i.e., $l_{i}=0$, if ${ }^{18}$

$$
\gamma(1-t)\left(y_{H}-y_{L}\right)>\delta\left(d_{H}-d_{L}\right)
$$

It is clear from this condition that $l_{i}^{*}(t)$ is non-decreasing in $t$. In other words, for given distances, a higher tax rate implies that the low status identity becomes relatively more attractive since redistribution benefits the low status group more. The higher the prevailing

\footnotetext{
${ }^{17}$ Furthermore, we implicitly assume that players aren't forward looking in the sense that they anticipate their own or others future tax and identity choices when making identity and voting decisions.

${ }^{18}$ In the unlikely event that an agent is indifferent between the two identities, we will assume that the agent chooses the low status identity.
} 
tax rate, the more likely it is that people identify with their low status identity, which in turn would imply that they vote for higher tax rates. Since the median tax rate is nondecreasing in the vector of tax rate choices, there is a complementarity between identity choices and the tax rate. This complementarity allows us to establish that at least one equilibrium exists (Proposition 1), but it also implies that there are potentially many equilibria. $^{19}$

Proposition 1 There exists at least one equilibrium.

All proofs are provided in the Appendix.

It is difficult to derive any general comparative statics without further specifying the model. In order to derive results for the effects of an increase in ethnic diversity that are not confounded by income differences between ethnic groups, we first study the simplest possible distribution of income.

Suppose there are only two income levels, $y_{R}>y_{P}>0$, and consequently two social classes, rich $(R)$ and poor $(P)$. The poor are in majority and all ethnic groups have same proportion of poor. From the expression for the most preferred tax rate (2) we see that these assumptions imply that the rich prefer zero taxes irrespective of how they identify themselves, and that the poor always prefer positive taxes. The median voter(s) must therefore be poor. From the condition for high status identification (3) it is clear that the identity choices of the poor only differ in the distances to the poor identity. The larger the ethnic group a poor individual belongs to, the smaller is the distance to the poor identity and the more likely she is to identify with the poor. There are only two possible equilibrium tax rates in this setting. In the high tax equilibrium, the poor in relatively large ethnic groups identify as poor and they are sufficiently many to create a majority for their preferred tax rate, which is high since they are altruistic toward the poor. In the low tax equilibrium, the poor in relatively small ethnic groups identify with their ethnic groups and are sufficiently many to be pivotal. This tax rate is lower since they are altruistic toward their ethnic groups that contain both rich and poor. ${ }^{20}$ Increasing the size of an existing ethnic group, or adding an ethnic group with the same proportion of poor as the already existing ones, implies that all other ethnic groups shrink in relative size, and

\footnotetext{
${ }^{19}$ The fact that the model has multiple equilibria for certain parameter values does not imply that each equilibrium is equally likely. Though not explicitly incorporated into the model, we would expect identity choices to exhibit a high degree of path dependence. A country with a history of ethnic tension is likely to stay in a low tax equilibrium even though the fundamental parameters are such that a high tax equilibrium is also feasible. Conversely, it may take a long time before immigration into countries that have historically been ethnically homogenous has an effect on identity choices and tax rates.

${ }^{20}$ There may of course also be equilibria where all poor identify either as poor or with their ethnic groups.
} 
consequently, that the distances to the poor identity increase. As long as the enlarged or added ethnic group is sufficiently small, the set of parameter values that can support the high tax equilibrium shrinks, which is stated in Proposition $2 .{ }^{21}$ Proposition 2 and the propositions that follow below provide conditions under which a change in parameters may render the initial equilibrium unfeasible. Hence, we do not consider the possibility that the economy may shift from one equilibrium to another in the presence of multiple equilibria.

Proposition 2 Let $p_{j}$ denote the proportion of the population belonging to ethnic group $j$. Suppose there are only two income levels, $y_{R}>y_{P}>0$, the poor are in majority and all ethnic groups contain the same proportion of poor. Then there is a threshold $\widehat{p}$ such that the poor of ethnic group $j$ identify with their ethnicity if $p_{j}<\widehat{p}$. Increasing the size of an existing ethnic group smaller than $\hat{p}$, or adding a new ethnic group that has the same proportion of poor as the pre-existing population and a size smaller than $\widehat{p}$, increases the proportion of poor that identify with their ethnic group and implies a weakly lower equilibrium tax rate.

In line with Proposition 2, several papers have shown empirically that there is a negative relation between ethnic heterogeneity and redistribution both across countries and between communities within countries. For example, Alesina et al. (2001) found social spending to be lower in countries with a high degree of racial fractionalization; Alesina et al. (1999) found a lower degree of public goods provision in ethnically fragmented metropolitan areas in the US, and Soss et al. (2001) found that when US states were given greater autonomy to set their own welfare policies, states with higher proportion of blacks implemented more punitive welfare regulations. Luttmer (2001) shows that support for welfare spending in the US is higher among people living in areas where the proportion of welfare recipients from their own racial group is high. Similarly, Orr (1976) found a negative correlation between aid to families with dependent children and the proportion of non-white welfare recipients across US states.

A seemingly paradoxical finding that our model can explain is why class voting, i.e., the extent to which voting behavior coincide with social class, seems to be particularly important in Scandinavian countries - which have the lowest income inequality in the world. Our answer is that the Scandinavian countries are relatively ethnically homogeneous, suggesting that the poor identify with their class. ${ }^{22}$ In line with this explanation, Nieuwbeerta

\footnotetext{
${ }^{21}$ Although Proposition 2 is stated in terms of a threshold $\widehat{p}$ that is not directly observable, the threshold can be indirectly inferred from initial identity choices (since ethnic groups identify differently depending on whether they are below or above the threshold).

${ }^{22}$ According to Nieuwbeerta and Ultee (1999), class voting was particularly important in the Scandinavian countries at least until the 1980s. Since then class voting has declined, but on the other hand the Scandinavian countries have also become more ethnically heterogenous due to immigration.
} 
and Ultee (1999) found a negative correlation between religious and ethnic diversity and the level of class voting.

Proposition 2 also suggests that members of small ethnic groups tend to identify with their ethnicity, which resonates well with the picture of New York in the 1960s described by Glazer and Moynihan (1970). ${ }^{23}$ A similar idea has also been used by the authoritarian former leader of Singapore, Lee Kuan Yew, to legitimize Singapore's one-party system:

In multiracial societies, you don't vote in accordance with your economic interests and social interests, you vote in accordance with race and religion. Supposing I'd run their system [democracy] here: Malays would vote for Muslims, Indians would vote for Indians, the Chinese would vote for Chinese. (Spiegel 2005, p. 23)

Although Lee Kuan Yew may be right that Malays and Indians in Singapore would vote for their own ethnic groups if they were allowed to vote, it is less clear that the Chinese would do so since they constitute roughly three quarters of the population. ${ }^{24}$

The idea that ethnic identification is stronger the smaller is the ethnic group is also in line with the study of ethnic minorities in the UK by Bisin et al. (2006). They find evidence that the higher is the percentage of a person's own ethnic group in the neighborhood, the lower is the degree of ethnic identification and the probability of homogamy. Similarly, Fryer and Torelli (2006) find that the phenomenon of 'acting white' among blacks - interpreted as racial differences in the relationship between academic performance and popularity - is stronger in US schools with few black students.

Finally, our model provides a simple argument for how a history of conflict between ethnic or social groups could affect the level of redistribution. As the ethnic tension parameter $(\beta)$ increases relative to class tensions $(\alpha)$, all individuals eventually identify with their ethnic group. Under the conditions in Proposition 2, this implies that the low tax equilibrium (in which the poor identify with their ethnic groups) will prevail for sufficiently high ethnic tensions and, correspondingly, that the high tax equilibrium (in which the poor identify with their class) will prevail if class tensions are sufficiently strong.

Proposition 2 requires quite strong assumptions on the distribution of income and size of ethnic groups. We therefore specify a simpler version of the model with only two ethnic groups, which allows us to study the effects of ethnic diversity and income inequality under less restrictive assumptions.

\footnotetext{
${ }^{23}$ The notion that members of small ethnic groups identify ethnically is consistent with the empirical evidence in Scheve and Slaughter (2001) showing that immigrants have more favorable attitudes toward immigration, also when income is controlled for.

${ }^{24}$ In all cases, it is a poor argument for not allowing the citizens of Singapore to vote.
} 


\section{Black and White Model}

In the remainder of the paper, we consider a simpler model with two social classes, poor $(P)$ and rich $(R)$, and two ethnic groups, black $(B)$ and white $(W)$. As we argue in Section 7 , we believe this simplification is relevant for the US, where the main ethnic division has traditionally been between the African-American population and people of European origin. The simplified model is also likely to be relevant for other countries - for example ethnic divisions between the native population and non-European immigrants in Europe and between the French and English speaking population of Canada.

We denote the proportion of the four different types in the population by $p_{P B}, p_{R B}, p_{P W}$ and $p_{R W}$ and as before we assume that all four types are represented in the population. In addition, we assume that no type, or sum of two or three types, consists of exactly half the population since this allows us to disregard the possibility of the median falling between two types' preferred tax rate.

We focus on the case when there are only two different income levels. In Appendix C, we consider the more realistic, but also more complicated, case when incomes are continuously distributed and show that the result in Proposition 3 is similar in that setting. Here we instead assume that the rich income group have pre-tax income $y_{R}$ and everybody in the poor group have income $y_{P}$ satisfying $y_{R}>y_{P}>0$. This specification implies that the status of the ethnic groups is in between the status of the poor and rich groups. In other words, the ethnic identity is the high status identity for poor people, whereas it is the low status identity for rich people.

Actual income distributions are typically skewed so that the median income is less than the average income. Since there are only two income levels in the model, we therefore assume that the poor population is in majority, i.e., $p_{P B}+p_{P W}>1 / 2$. Without loss of generality, we also assume that the white population is in majority, i.e., $p_{P W}+p_{R W}>1 / 2$. Given these assumptions, we have two different cases. First, if poor whites are in majority, the tax rate is uniquely determined by their identity choice. Second, if poor whites do not constitute a majority of the population, both poor whites and poor blacks could potentially determine the tax rate. We assume that the white and black population have the same average income, i.e., $p_{R W} / p_{P W}=p_{R B} / p_{P B}$. In Appendix B, we derive formal results also for the case when the white population is richer on average, i.e., $p_{R W} / p_{P W}>p_{R B} / p_{P B}$.

The distance function $d(\cdot)$ is given by the following table: 
Poor black Poor white Rich black Rich white

$$
\begin{array}{lcccc}
\text { Black } & \alpha \frac{p_{R B}}{p_{P B}+p_{R B}} & & \alpha \frac{p_{P B}}{p_{P B}+p_{R B}} & \\
\text { White } & & \alpha \frac{p_{R W}}{p_{P W}+p_{R W}} & & \alpha \frac{p_{P W}}{p_{P W}+p_{R W}} \\
\text { Poor } & \beta \frac{p_{P W}}{p_{P B}+p_{P W}} & \beta \frac{p_{P B}}{p_{P B}+p_{P W}} & & \\
\text { Rich } & & & \beta \frac{p_{R W}}{p_{R B}+p_{R W}} & \beta \frac{p_{R B}}{p_{R B}+p_{R W}}
\end{array}
$$

This linear specification implies that it is costless to identify with a group where everybody is of the same type as oneself, whereas the cost goes to $\alpha$ or $\beta$ when there are nobody like oneself in that group.

We now turn to determining the equilibria of this model. First, recall from (2) that the optimal tax rate of someone belonging to social class $j$ and ethnic group $k$ that identifies with his social class $j$ is given by:

$$
t_{j k j}^{*}=\max \left\{1-\frac{y_{j}}{y}, 0\right\}
$$

It is clear that rich people who identify themselves as rich prefer a zero tax rate (since $\left.y_{R}>y\right)$ and that poor people who identify themselves as poor prefer the tax rate $1-y_{P} / y$. Similarly, someone identifying with her ethnic group $k$ prefers the tax rate

$$
t_{j k k}^{*}=\max \left\{1-\frac{y_{j}+\gamma y_{k}}{(1+\gamma) y}, 0\right\}
$$

The optimal voting choices (4) and (5) imply that preferred tax rates can be ordered within ethnic groups - for example, rich whites always prefer lower taxes than poor whites.

Lemma 1 Optimal tax rates always satisfy the following:

(i) $0=t_{R W R}^{*} \leq t_{R W W}^{*} \leq t_{P W W}^{*} \leq t_{P W P}^{*}=1-y_{P} / y$,

(ii) $0=t_{R B R}^{*} \leq t_{R B B}^{*} \leq t_{P B B}^{*} \leq t_{P B P}^{*}=1-y_{P} / y$.

In addition, if whites are richer than blacks, then $t_{R W W}^{*} \leq t_{R B B}^{*}$ and $t_{P W W}^{*} \leq t_{P B B}^{*}$.

Lemma 1 implies that when whites are richer than blacks and all types identify with their ethnic group, blacks prefer the same or higher taxes than whites holding income constant. Fong (2001), Alesina et al. (2001) and Alesina and La Ferrara (2005b) show empirically that white people in the US are more negative toward redistribution than African-Americans also when personal income is held constant. This suggests that the poor in the US identify along ethnic lines rather than with their social class.

If whites are richer than blacks, the status of the ethnic identity is higher for poor whites than for poor blacks. However, that whites are richer also means that the distance 
for poor whites to the white identity is larger than the distance for poor blacks to the black identity. It is possible to show that the latter effect dominates and that poor blacks always identify as black if poor whites identify as white. This result is dependent on the linear specification of the distance function and the assumption that the class and ethnic tension parameters are the same for all types, but it is also plausible - if the poor in the majority group favor their ethnic group, then we would probably not expect the poor in the minority group to identify with the poor.

Lemma 2 If whites have the same or higher average income than blacks and poor whites identify as white, then poor blacks identify as black.

From Proposition 1 we know that at least one equilibrium exists. Since we have assumed that the poor are in majority, we can show that only the identity choices of the poor matter for the equilibrium tax rate. When whites and blacks are equally rich, there can only be two different tax rates in equilibrium since poor whites and poor blacks prefer the same tax rate when they make the same identity choice. For simplicity, we denote the two possible equilibrium tax rates the poor $\left(t_{P W P}^{*}=t_{P B P}^{*}\right)$ and ethnic $\left(t_{P W W}^{*}=t_{P B B}^{*}\right)$ tax rate.

Lemma 3 If blacks and whites have the same average income, then there are two feasible equilibrium tax rates:

1. If poor whites are in majority and identify as white, or if poor whites are in minority and poor blacks identify as black, the equilibrium tax rate will be the ethnic tax rate $\left(t_{P W W}^{*}=t_{P B B}^{*}=1-\left(y_{P}+\gamma y\right) /(1+\gamma) y\right)$.

2. If poor whites are in majority and identify as poor, or if poor whites are in minority and poor blacks identify as poor, the equilibrium tax rate will be the poor tax rate $\left(t_{P B P}^{*}=t_{P W P}^{*}=1-y_{P} / y\right)$.

A feature of the model is that there might be multiple equilibria which implies that an equilibrium can be suboptimal in the sense that each agent of a certain type would reach a higher utility level if the other agents of the same type changed identity and preferred tax rate. However, given the identity choices of the other agents, no agent has an incentive to change identity or vote differently. ${ }^{25}$ For example, we might have one high tax equilibrium where poor whites identify as poor and one low tax equilibrium where they identify as

\footnotetext{
${ }^{25}$ Since voting and identity choices are made separately, an agent can end up in a suboptimal equilibrium even if he is the only agent in the economy (and distances are defined so that this is possible). A single agent might prefer to simultaneously switch identity and preferred tax rate, but this is ruled out by the definition of an equilibrium.
} 
white. Based on Marxist thinking it might be tempting to conclude that the poor are better off in a high tax equilibrium, and that the poor should be made "class conscious" if the low tax equilibrium prevails. However, although a class identity would benefit their material interest, our model allows no such conclusion since agents also get utility from their identity - it may well be the case that the poor's utility is lower in a high tax than in a low tax equilibrium. ${ }^{26}$

Although differences in redistribution can be explained in terms of multiple equilibria for identical parameter values, we now go on to study how the set of potential equilibria changes with the parameters of the model. These results together with some empirical evidence are presented in the following three sections.

\section{Ethnic Diversity}

The main lesson from Proposition 2 is that ethnic diversity might induce the poor to identify with their ethnic group and therefore favor lower taxes. In this section we will see that this conclusion does not hold universally.

In the black and white model, blacks constitute a minority and we therefore model an increase of ethnic diversity as an increase in the black population. The effect of an increase in the number of blacks depends both on whether poor whites are in majority and the extent of interethnic income inequality. When poor whites are in majority, their identity choices alone determine the tax rate, whereas the tax rate also depends on identity choices of poor blacks when poor whites are in minority. The formal results in this section focus on an increase in the proportion of blacks when whites and blacks have the same average income. The case when blacks are on average poorer is shown formally in Appendix B.

When blacks and whites are equally rich and the proportion of poor and rich blacks increases proportionally, the only effect of an increase in the proportion of blacks on identity choices is to increase the distance to the class identity for poor whites and decrease it for poor blacks. The relative status of both identities and distance to the ethnic identity is unaffected by changes in ethnic diversity. As the proportion of blacks increases, poor blacks therefore become more prone to identify as poor whereas poor whites become more prone to identify as white. As stated in the following proposition, this implies that the tax rate is unchanged or decreases when poor whites are in majority, whereas it is unchanged or increases when they are not.

\footnotetext{
${ }^{26}$ More generally, the idea that people may hold dysfunctional identities is often raised in the literature on identity and may be important in order to understand self-destructive behaviors such as "ghetto culture" (see Akerlof and Kranton 2000 for references and further discussion).
} 
Proposition 3 Suppose blacks and whites have the same average income. If poor whites are in majority, then an increase in the black population implies the following for the equilibrium tax rate:

1. If poor whites initially identify as poor, then poor whites might to switch to the white identity resulting in a lower equilibrium tax rate.

2. If poor whites initially identify as white, nothing happens to identity choices and tax rates.

If poor whites are in minority, then an increase in the black population implies the following for the equilibrium tax rate:

1. If poor whites initially identify as white or both poor whites and poor blacks identify as poor, then the tax rate is unchanged.

2. If poor whites initially identify as poor and poor blacks identify as black, then poor blacks might switch to the poor identity resulting in a higher equilibrium tax rate.

To illustrate the full comparative statics, we consider two parametric examples (illustrated in Figure 1) with different status parameters. The thin dashed vertical line in Figure 1 indicates the proportion of blacks above which poor whites are in minority.

Figure 1. Increase in ethnic diversity (no interethnic income inequality)

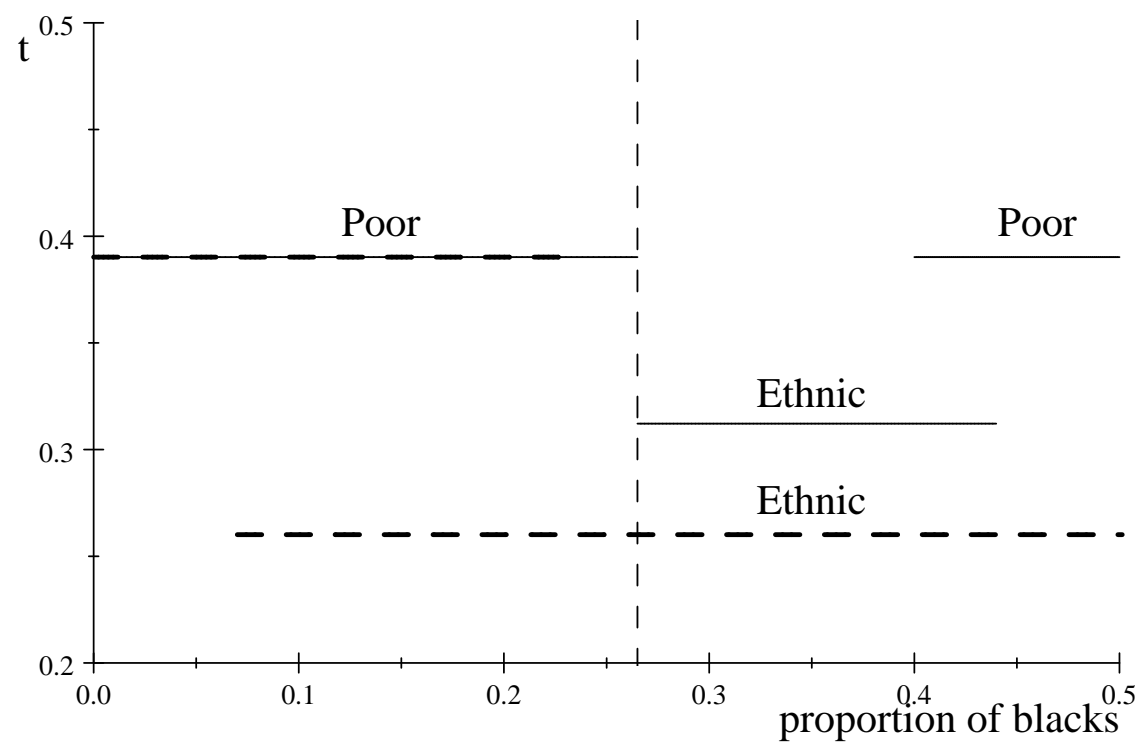

Thick dashed lines: High status $(\gamma=0.5)$. Thin lines: Low status $(\gamma=0.25)$. 
The thick dashed horizontal line in Figure 1 indicates the equilibrium tax rate as a function of the proportion of blacks when agents care relatively much about the status of the group they identify with $(\gamma=0.5) .{ }^{27}$ The more important is status, the more likely it is that poor blacks and poor whites identify with their respective ethnic groups. In this example, the status parameter is so high that poor blacks always identify themselves as black. Poor whites, on the other hand, identify as poor when society is ethnically homogenous (less than 7 percent blacks) and the higher poor tax rate is the only possible equilibrium. The poor tax rate is an equilibrium also when the proportion of blacks is between 7 and 24 percent. However, since poor whites now identify as white at the lower ethnic tax rate, this can also be an equilibrium. When the proportion of blacks is above 24 percent, poor whites identify as white at all tax rates and only the ethnic tax rate is an equilibrium. Hence, poor whites already identify as white at the point when they become a minority (at 27 percent blacks), implying that the tax rate is unaffected by this shift in potential majorities.

The equilibrium tax rate in the second parametric example is indicated by the thin lines in Figure 1. The only difference compared to the previous example is that status is less important $(\gamma=0.25$ compared to $\gamma=0.50)$, which has two different effects: It makes it more likely that the poor identify with their social class, and it leads to a higher ethnic tax rate. In this example, poor whites always identify as poor. When the proportion of blacks is below 27 percent, poor whites are in majority and since they always identify as poor, the poor tax is implemented. If the proportion of blacks is between 27 and 40 percent, poor whites are not in majority and, since poor blacks identify as black at both tax rates, only the ethnic tax rate is an equilibrium. When the proportion of blacks is between 40 and 44 percent, poor blacks identify as poor at the poor tax rate and as black at the ethnic tax rate, implying that both tax rates are equilibria. Finally, as the proportion of blacks is above 44 percent, poor blacks identify as poor at all tax rates and only the poor tax rate can be an equilibrium.

Note that though the effect of ethnic diversity on redistribution was monotonic and negative in the first parametric example, this is not the case in the second example. Instead, redistribution is high when ethnic diversity is either very low or very high. In the intermediate case, there are enough blacks to influence the tax rate, but so few that poor blacks are reluctant to identify with the poor. This provides an explanation for the finding in Dincer and Lambert (2006) that there is a U-shaped relationship between redistribution and ethnic fractionalization and polarization across US states. ${ }^{28}$

\footnotetext{
${ }^{27}$ The parameters used in this example are $p_{P}=0.68, y_{P}=100, y_{R}=300, \gamma=0.50, \delta=20, \alpha=4$ and $\beta=1.3$.

${ }^{28}$ Dincer and Lambert (2006) report that the relationship between fractionalization and redistribution is U-shaped, but do unfortunately not state the sign of the square of their measure of ethnic polarization, just
} 
Proposition 3 only applies to the case when blacks and whites have the same income. In many societies, the minority population is poorer than the majority group. In this case, increasing the size of the minority group decreases the average income in the population, leading to lower tax rates for given identity choices. We analyze this case formally in Proposition B1 and the results are similar to Proposition 3. One difference, however, is that there are three instead of two potential equilibrium tax rates. Since the black group is poorer than the white group, poor blacks now favor higher taxes when they identify as black than poor whites who identify as white.

So far we have assumed that the number of poor blacks and rich blacks increase proportionally, ensuring that the incomes of the black and white groups are held constant. In many cases, for example immigration, it is more reasonable to assume that it is only the proportion of poor blacks that increases. This implies a change in income inequality both within and between the two ethnic groups, which introduces a more intricate interaction between social class and ethnicity. In Proposition B2, we consider an increase in the proportion of blacks among the poor, holding the average income of the population constant. One way to think about this case is as an inflow of poor black immigrants. Such an inflow has counteracting effects on the identity choices of poor blacks. On the one hand, the status of the black identity decreases (since blacks become poorer on average) while the perceived similarity to the poor identity increases (since the proportion of blacks among the poor increases). These two effects make it more likely that poor blacks identify as poor and favor high taxes. On the other hand, as the proportion of poor among blacks increases, poor blacks perceive themselves as more similar to the black group. If the black group is initially small, the latter effect dominates and immigration of poor blacks might induce poor blacks to switch identity from "poor" to "black" and favor less redistribution. Somewhat paradoxically, an increase in the proportion of poor blacks may therefore reduce the support for redistribution also among poor blacks. Note that the mechanism behind this non-monotinicity is different compared to the example in Figure 1. In that example, the non-monotonicity was induced by a shift in the set of potential majorities, whereas it is the actual identity choices that are non-monotonic in Proposition B2.

The results for ethnic diversity may shed some light on the evidence on class voting, i.e., the extent to which social class determines voting behavior (see Nieuwbeerta and Ultee 1999 for references to this sociological literature). The model suggests that immigration of foreign low-skilled people might induce poor whites - and possibly also poor blacks to identify with their ethnic group and support lower taxes. The inflow of relatively poor

that it is statistically significant in all specifications. However, their graphical evidence strongly suggests that the relationship between ethnic polarization and redistribution is U-shaped. We have contacted the authors in order to clarify this point, but are still awaiting a response. Note also that since we only have two ethnic groups in the model, we cannot distinguish between ethnic fractionalization and polarization. 
immigrants may therefore be part of the explanation for why class voting has declined in Europe during the last decades, as well as why European anti-immigration political parties seem to have gained in popularity. ${ }^{29}$ The latter is supported by empirical studies by Knigge (1998) and Golder (2003) showing that the support for anti-immigration parties is indeed increasing in the level of immigration. A competing explanation for the relatively strong support that anti-immigration parties get from the working class is a fear for increased competition in the labor market. However, in contrast to our model, this does not explain why these parties often advocate a low level of redistribution (see for example Betz 1993, Poglia Mileti et al. 2002 and McGann and Kitschelt 2005). ${ }^{30}$ In addition, the empirical evidence on the relationship between support for anti-immigration parties and the level of unemployment is ambiguous (see Knigge 1998 and Golder 2003). ${ }^{31}$

\section{Income Inequality}

Income inequality can mean two different things in this model - the income difference between social classes and the difference in income between ethnic groups. We first analyze the effects of income inequality between rich and poor.

Standard models of income redistribution, e.g. Meltzer and Richard (1981), predict that redistribution increases as a response to an increase in pre-tax income inequality as measured by the distance between the average and median income. When income inequality increases, the poor become poorer compared to the rich which increases their demand for redistribution. In our model there is a counteracting effect since an increase in income inequality increases the status of ethnic identities, which might lead to a shift to ethnic identities and lower tax rates. Since the comparative statics are considerably more complicated if blacks are poorer than whites, without bringing many additional insights, Proposition 4 is only stated for the case when whites and blacks have the same average income. ${ }^{32}$

\footnotetext{
${ }^{29}$ Examples of such parties include FPÖ (Austria), Schweizerische Volkspartei (Switzerland), Dansk Folkeparti (Denmark), Vlaams Blok (Belgium), Fremskridtspartiet (Norway) and Front national (France).

${ }^{30}$ The political bundling effect in a two-dimensional policy space demonstrated by Roemer (1998) can explain why a voter could vote for a right-wing party although she favors a high degree of redistribution, but not why anti-immigration parties tend to focus on right-wing economic policies in the first place.

${ }^{31}$ Of course, the absence of any relation between the unemployment rate and anti-immigration sentiments is only an argument against the labor market hypothesis if agents are not perfectly forward-looking regarding the effects of increased immigration, but adjust their beliefs about negative effects of immigration in response to a high level of unemployment.

${ }^{32}$ Proposition 4 is only stated for the case when poor whites are in minority since the case when poor whites are in majority follows directly once it is noted that the identity choices of poor blacks do not affect the equilibrium.
} 
Proposition 4 If poor whites are in minority and if whites and blacks have the same average income, then an increase in pre-tax income inequality $\left(y_{R}-y_{P}\right)$, while average income $y$ is held constant, implies the following for the equilibrium tax rate:

1. If poor blacks identify as black, the tax rate increases. Furthermore, if in addition income inequality is high $\left(y_{P} / y<(1-\gamma) / 2\right)$, poor blacks (and possibly poor whites) might switch to the poor identity which increases the tax rate further. If income inequality instead is low $\left(y_{P} / y>(1-\gamma) / 2\right)$, the identity choices of poor blacks are unchanged.

2. If poor whites and poor blacks initially identify as poor, the tax rate increases and the identity choices of the poor are unchanged if income inequality is high $\left(y_{P} / y<1 / 2\right)$. If instead income inequality is low $\left(y_{P} / y>1 / 2\right)$, poor blacks (and possibly poor whites) might switch to ethnic identities which leads to a lower tax rate.

As can be seen in Proposition 4, the effect of an increase in pre-tax income inequality depends on the initial degree of income inequality. If income inequality is initially high, the tax rate increases so much in response to an increase in pre-tax income inequality that aftertax income inequality decreases, which decreases the relative status of the ethnic identities. On the other hand, if income inequality is initially low, after-tax income inequality increases and the ethnic identities become more attractive.

To see why this is the case, note that an increase in income inequality has two counteracting effects on the relative status of ethnic and poor identities. For given tax rates, higher pre-tax income inequality implies that the ethnic identities become more attractive for poor blacks and poor whites. On the other hand, for given identity choices, the tax rate increases as a response to higher inequality, which makes the poor identities more attractive. To see these two effects, note that the status difference between the ethnic and class identities is some population parameter times $(1-t)\left(y_{R}-y_{P}\right) \cdot{ }^{33}$ Differentiating with respect to $y_{R}-y_{P}$ gives

$$
\frac{\partial(1-t)\left(y_{R}-y_{P}\right)}{\partial\left(y_{R}-y_{P}\right)}=(1-t)-\frac{\partial t}{\partial\left(y_{R}-y_{P}\right)}\left(y_{R}-y_{P}\right)
$$

The first term in this expression is the direct effect of income inequality, whereas the second term is the effect through the increase in the tax rate. Since $\partial t / \partial\left(y_{R}-y_{P}\right)$ does not depend on $y_{R}-y_{P}$, this latter effect is stronger if income inequality is initially high.

\footnotetext{
${ }^{33}$ One way to see this is to consider the conditions for ethnic identification for poor blacks and poor whites in the Appendix, i.e., A1 and A2.
} 
The result that an increase in income inequality has ambiguous effects on redistribution fits well with recent empirical evidence showing no clear connection between income inequality and redistribution (see Perotti 1996 and Lind 2005). However, our model is not the first to produce this result. For example, in Corneo and Grüner (2000) the median voter prefers less redistribution as economic inequality increases, since the cost of taxation in terms of lost social prestige relative to the working class increases with economic inequality. The result that an increase in pre-tax income inequality might induce the poor to switch identity and thus favor lower taxes is also present in a slightly different flavor in Shayo (2009).

The model also allows us to study the effect of a change in income differences across ethnic groups. In Proposition B3, we model interethnic income inequality as an increase in the number of poor blacks and a corresponding decrease in the number of poor whites, while the total number of poor and blacks is held constant. ${ }^{34}$ The main prediction is that the level of redistribution falls as interethnic income inequality increases if the black minority group is small, but might increase if the black group is large. This results is partly in line with the theoretical and empirical results provided by Lind (2007), who argues that interethnic inequality reduces the support for redistribution. ${ }^{35}$ The novel idea behind our result is that higher income inequality between ethnic groups might induce the poor of the majority group to switch to their ethnic identity in order to enjoy the higher status of their ethnic group.

\section{Social Mobility}

A recent literature has argued that beliefs about the causes of poverty is an important determinant of attitudes toward redistribution. ${ }^{36}$ Alesina et al. (2001) and Fong (2001) show empirically that the belief that poverty is caused by laziness and not bad luck is a strong predictor of negative attitudes toward redistribution. ${ }^{37}$ Arguably, if the poor believe that the rich have worked hard for their higher incomes, they are less likely to feel aversion

\footnotetext{
${ }^{34}$ Studying interethnic inequality in this way implies that the distances are affected, whereas these are unaffected by a change in standard income inequality. In a model with more than two income groups, interethnic inequality could instead be analyzed as income changes that wouldn't affect distances.

${ }^{35}$ Lind (2007) shows this theoretically in a model where people's altruism are targeted towards their own group. He also provides somewhat weak empirial support that between group inequality reduces the support for redistribution (using U.S. panel data from 1969 to 2000).

${ }^{36}$ See for example Piketty (1995), Alesina and Angeletos (2005) and Bénabou and Tirole (2006) for models where such beliefs are endogenously determined.

${ }^{37}$ Gilens (1999, p. 172-173) develops a similar argument: "The belief that black Americans lack commitment to the work ethic is central to whites' opposition to welfare. But it appears that this race-based opposition does not primarily reflect either a general racial animosity or an effort to defend whites' concrete group interests. Rather, the racial component of white opposition to welfare seems to reflect the most important nonracial basis of welfare opposition: the perception that welfare recipients are undeserving."
} 
toward the rich. Conversely, the rich would feel more sympathetic toward the poor if they thought that poverty was caused by bad luck instead of laziness.

Beliefs about social mobility can be incorporated into our model in a reduced form way through the class tension parameter, $\alpha$. In the original model, a high $\alpha$ push both the rich and the poor toward identifying with their social class. However, the belief that poverty is caused by laziness should have differential effects depending on social class: the rich should be more likely to identify with their social class the stronger is this belief while the poor should be more prone to identify with their ethnic group. To incorporate this in the model, we reinterpret $\alpha$ as the prevalence of the belief that "poverty is caused by laziness" and replace $\alpha$ by $1 / \alpha$ in the distance functions to the ethnic identity for poor blacks and poor whites. In this case, a high $\alpha$ tend to push the rich toward class identification, whereas the poor are pushed toward ethnic identification. This provides a simple argument for why beliefs about the causes of poverty may matter for redistribution. Strong beliefs that poverty is caused by laziness make it more likely that the poor identify with their ethnic group, which in turn implies low taxes (compared to the case with class identification). Such beliefs are of course likely to directly affect preferences for redistribution, but the possibility of identity shifts demonstrates an extra channel through which those beliefs may lead to lower redistribution.

\section{American Exceptionalism}

Why is redistribution so much lower in the US compared to Western Europe? In terms of our model, the US population of European origin are referred to as "white", whereas the African American population is referred to as "black". ${ }^{38}$ This is a simplification since people of Hispanic origin now constitute a larger share of the US population than African Americans. However, the increase of the Hispanic population in the US is a relatively recent phenomenon, and we believe the relationship between US citizens of European descent and African Americans to be of particular importance for understanding redistributive policies. ${ }^{39}$ Moreover, the thrust of the argument outlined below would not change if the model were to be extended with a third "Hispanic" ethnic group. In case of Western Europe, we refer to the native population as "white" and immigrants of non-European descent as "black". We point to three aspects of our model of particular relevance for

\footnotetext{
${ }^{38}$ Based on survey data on self-reported social class, the restriction to two social classes seems relevant for the US. For example, in the General Social Surveys 1972-2004 (Davis et al. 2005), 46 percent of respondents classify themselves as working class, whereas 46 percent classify themselves as middle class. Of the remaining 8 percent, 5 percent classify themselves as lower class and 3 percent as upper class.

${ }^{39}$ This has also been the focus in the literature on racial issues in the US, with Myrdal (1944) as the classic reference. Loury (2002) provides a more recent account on racial stigmatization in the US.
} 
understanding the comparably low level of redistribution in the US.

First, pre-tax income inequality is higher in the US than in Western Europe. On the one hand, the tax preferred by the poor is increasing in income inequality for given identities. On the other hand, if income inequality in the US and Western Europe is lower than the threshold in Proposition 4, then the higher level of income inequality in the US will make the poor more likely to identify with their ethnic group. Hence, the effect on redistribution from the higher pre-tax income inequality in the US is ambiguous.

Second, the higher degree of ethnic diversity in the US may imply that poor whites in the US are more likely to identify as white and favor a low level of redistribution. Similarly, to the extent that interethnic income inequality is higher in the US, Proposition B3 shows that this might be an additional force in the same direction. Moreover, the preferred tax rate of poor whites when they identify themselves as white is decreasing in the affluence of whites. Hence, to the extent that whites in the US are more wealthy than their counterparts in Europe, poor whites in the US who identify as white favor a lower tax rate than poor whites in Europe identifying as white, holding everything else constant.

Third, Americans are much more prone than Europeans to believe that the poor are lazy rather than unlucky. In addition, the US has historically a more troubled racial relationship than most European countries. Both of these differences suggest that the poor whites should be more likely to identify as white in the US.

These different explanations do not yield an unambiguous prediction, but, given the argument above, it indeed seems plausible that poor white Americans should be more likely to identify as white and favor low taxes than poor white Europeans. It should be noted, however, that the difference in redistribution between the US and Western Europe could also be rationalized in terms of multiple equilibria. ${ }^{40}$ Even if the US and Western Europe were identical in terms fundamentals (i.e., parameter values), it could be the case that poor whites in Europe identify as poor simply because redistribution is relatively high if redistribution had been at US levels they would have switched to ethnic identities and supported lower taxes.

We are not the first to raise the argument that ethnic diversity is important in explaining differences in redistribution between the US and Europe. Shayo (2009) argues that a high degree of ethnic diversity concentrated to the poorer segments of society induces the poor to identify with their nation instead of their class, thereby reducing the support for redistribution. Alesina et al. (2001) claim that differences in beliefs about the poor and ethnic heterogeneity explains the comparably low level of redistribution in the US through

\footnotetext{
${ }^{40}$ Several other economists have also argued that differences in the level of redistribution across countries can be understood in terms of multiple equilibria. See Alesina and Angeletis (2005) and Bénabou and Tirole (2006) for two recent contributions.
} 
its impact on altruism. However, since altruism is itself an exogenous parameter in their theoretical framework, they do not explicitly model how these factors explain altruism. Moreover, Alesina et al. (2001) consider altruism to be nondiscriminatory across groups, whereas altruism in our model is only directed at a particular subgroup of the population. Lind (2007) studies such directed altruism, but unlike our approach the decision to sympathize with a particular subgroup is not endogenous in his model.

\section{Concluding Remarks}

Understanding differences in redistribution across countries and over time is a key question for political science and economics. We contribute to this literature by developing a model where both identity choices and redistribution are endogenous. The model addresses a number empirical regularities that are hard to reconcile with the standard model of redistribution, primarily that ethnic diversity generally is associated with lower levels of redistribution.

Though our model can explain these patterns, it also suggests that the relationship between ethnic diversity and redistribution is more complex than acknowledged in the previous literature. The model predicts that complete ethnic homogeneity leads to high taxes, but the effect of increases in ethnic diversity from moderate or high levels is ambiguous. As the size of a small minority group increases, the poor in the majority group become more prone to identify with their ethnic group and vote for low taxes. On the other hand, the poor in the minority group become more prone to identify with their social class and support high taxes. Moreover, even if identity choices remain unchanged, an increase in the size of a minority group could change tax rates as ethnic minorities are more likely to identify with their ethnic group.

Our model also provides an explanation for why high pre-tax income inequality is not always associated with high taxes, in contrast to what one would expect from the standard model. While the poor have a stronger material self-interest in high tax rates the higher is income inequality, their immaterial incentive to identify with their ethnic group might also increase with income inequality. This leads to the seemingly paradoxical result that class identification may be more prevalent in societies with small income differences between social classes.

The model discussed in this paper could be extended in several ways. For example, one could add a middle class identity or a third ethnic group to the model. A more challenging tasks is to endogenize the social categories individuals can identify with. The notion that such social categorizations may change over time is discussed by, for example, Alesina and La Ferrara 2005a and Posner 2005. Relatedly, groups may have incentives to manipulate 
the identity choices of others. For example, the rich might try to reduce the level of redistribution by convincing the poor to identify with their ethnic group. This could be done by directly influencing their identity choice through propaganda, or, more indirectly, by trying to create new ethnic categories. 


\section{Appendix A: Proofs}

\section{A.1 Proof of Proposition 1}

We know that $l_{i}^{*}(t)$ is non-decreasing in $t$ and that $t_{i}^{*}\left(l_{i}\right)$ is non-decreasing in $l_{i}$. Consequently, $t_{i}^{*}\left(l_{i}^{*}(t)\right)$ is non-decreasing in $t$, which implies that the median tax is non-decreasing in $t$. Equilibrium tax rates are given by the fixed points of $\Gamma\left(\times_{i \in N} t_{i}^{*}\left(l_{i}^{*}(t)\right)\right)$. Note that this is a non-decreasing mapping $\Gamma(t):[0,1] \rightarrow[0,1]$. This mapping will typically not be continuous, but since it is a non-decreasing mapping from the unit interval to the unit interval, Tarski's fixed point theorem implies that there is at least one fixed point of $\Gamma(t)$ (see Theorem M.I.3 in Mas-Colell et al. 1995).

\section{A.2 Proof of Proposition 2}

It is clear from (2) that the poor always prefer positive tax rates, the rich prefer zero taxes, and that preferred tax rates for given identity choices is unchanged when the composition of ethnic groups changes. Since the poor are in majority, the median voter(s) is poor. The average incomes and distances to the ethnic groups are the same for all ethnic groups and do not change as the composition of ethnic groups changes. Let the average income in the ethnic groups be denoted by $y_{E}$ and the distances by $d_{E}$. Letting $p_{j}$ denote the proportion of the population belonging to ethnic group $j$, we can re-write the distance to the poor identity for a poor person in this ethnic group as $d_{P j P}=d\left(\beta\left(1-p_{j}\right)\right)$. The condition for ethnic identification (3) implies that the poor in ethnic group $j$ identify with their ethnic group if

$$
d\left(\beta\left(1-p_{j}\right)\right)>d_{E}-\gamma(1-t)\left(y_{E}-y_{P}\right) / \delta .
$$

In other words, the higher $p_{j}$ is, the lower is the distance to the poor identity and the more likely is identification with the poor. This implies that there for a given tax rate $t$ is a threshold $p(t)$ such that the poor in ethnic groups larger than $p(t)$ identify with the poor, and the poor in smaller ethnic groups identify with their ethnic group. This threshold is decreasing in $t$ - the higher the tax rate is, the smaller an ethnic group must be for its members to identify with the ethnic group. Let $t_{P}$ denote the tax rate preferred by the poor when identifying as poor and define $\widehat{p}=p\left(t_{P}\right)$. It is clear that poor in the ethnic groups smaller than $\widehat{p}$ will always identify with their ethnic group irrespective of the equilibrium tax rate.

Suppose first that sufficiently many of the poor identify as poor so that the high tax rate $t_{P}$ prevails. Increasing the size of an ethnic group or adding a new ethnic group could then lead some of the poor to switch to ethnic identities, which may result in the low 
equilibrium tax rate. (The new low equilibrium tax rate may in turn induce the poor in other ethnic groups to switch to ethnic identities.)

Now suppose instead the sufficiently many poor initially identified with their ethnic groups so that the low tax rate preferred by poor identifying with their ethnic group prevails. Enlarging or adding one ethnic group may then induce some of the poor in the other groups to switch to ethnic identities (since these become smaller). However, we want to rule out that the enlarged or new group is not so large that the poor in that group identify with the poor. This cannot happen if the group is smaller than $\widehat{p}$.

\section{A.3 Proof of Lemma 1}

The result follows directly from (4) and (5) once it is noted that $y_{P}<y_{W}<y_{R}$ and $y_{P}<y_{B}<y_{R}$ for the first part, and $y_{W}>y_{B}$ for the second.

\section{A.4 Identity Inequalities: Black and White model}

The condition (3) for high status identification can be rewritten as follows for poor blacks and poor whites:

$$
\begin{gathered}
P B:(1-t) \frac{p_{R B}}{p_{P B}+p_{R B}}\left(y_{R}-y_{P}\right)>\frac{\delta}{\gamma}\left(\alpha \frac{p_{R B}}{p_{P B}+p_{R B}}-\beta \frac{p_{P W}}{p_{P B}+p_{P W}}\right), \\
P W:(1-t) \frac{p_{R W}}{p_{P W}+p_{R W}}\left(y_{R}-y_{P}\right)>\frac{\delta}{\gamma}\left(\alpha \frac{p_{R W}}{p_{P W}+p_{R W}}-\beta \frac{p_{P B}}{p_{P B}+p_{P W}}\right) .
\end{gathered}
$$

For several of the proofs it is useful to rewrite the two inequalities (A1) and (A2) as follows by dividing by $p_{R B} /\left(p_{P B}+p_{R B}\right)$ and $p_{R W} /\left(p_{P W}+p_{R W}\right)$, respectively:

$$
\begin{gathered}
P B: \frac{p_{P W}}{p_{P B}+p_{P W}} \frac{p_{P B}+p_{R B}}{p_{R B}}>\frac{1}{\beta}\left(\alpha-\frac{\gamma}{\delta}(1-t)\left(y_{R}-y_{P}\right)\right), \\
P W: \frac{p_{P B}}{p_{P B}+p_{P W}} \frac{p_{P W}+p_{R W}}{p_{R W}}>\frac{1}{\beta}\left(\alpha-\frac{\gamma}{\delta}(1-t)\left(y_{R}-y_{P}\right)\right) .
\end{gathered}
$$

\section{A.5 Proof of Lemma 2}

We want show that the left hand side of (A3) is larger than the left hand side of (A4). Rearranging this condition we get

$$
p_{P W} \frac{p_{R W}}{p_{P W}+p_{R W}}>p_{P B} \frac{p_{R B}}{p_{P B}+p_{R B}} .
$$

If white and black have the same average income, we only need to show that $p_{P W}>$ $p_{P B}$. This follows from the fact that whites are in majority and that blacks and whites 
have the same average income (to see this, divide $p_{R W}+p_{P W}>p_{P B}+p_{R B}$ by $p_{P B}$ and substitute $\left.p_{R B} / p_{P B}=p_{R W} / p_{P W}\right)$. Now suppose that whites are on average richer than blacks. Rewriting the above condition, we get

$$
\frac{p_{P W}}{p_{P W}+p_{R W}} \frac{p_{R W}}{p_{P W}+p_{R W}}\left(p_{P W}+p_{R W}\right)>\frac{p_{P B}}{p_{P B}+p_{R B}} \frac{p_{R B}}{p_{P B}+p_{R B}}\left(p_{P B}+p_{R B}\right) .
$$

We know that $p_{P W}+p_{R W}>p_{P B}+p_{R B}$ so it is sufficient to show that

$$
\frac{p_{P W}}{p_{P W}+p_{R W}} \frac{p_{R W}}{p_{P W}+p_{R W}}>\frac{p_{P B}}{p_{P B}+p_{R B}} \frac{p_{R B}}{p_{P B}+p_{R B}} .
$$

Using that $p_{R W} /\left(p_{P W}+p_{R W}\right)=1-p_{P W} /\left(p_{P W}+p_{R W}\right)$ (and similarly for blacks) we can rewrite this condition as

$$
\left(\frac{p_{P B}}{p_{P B}+p_{R B}}\right)^{2}-\left(\frac{p_{P W}}{p_{P W}+p_{R W}}\right)^{2}>\frac{p_{P B}}{p_{P B}+p_{R B}}-\frac{p_{P W}}{p_{P W}+p_{R W}} .
$$

Since whites are richer than blacks, both the left and right hand sides of this expression are positive. The left hand side can be rewritten as

$$
\left(\frac{p_{P B}}{p_{P B}+p_{R B}}+\frac{p_{P W}}{p_{P W}+p_{R W}}\right)\left(\frac{p_{P B}}{p_{P B}+p_{R B}}-\frac{p_{P W}}{p_{P W}+p_{R W}}\right)>\left(\frac{p_{P B}}{p_{P B}+p_{R B}}-\frac{p_{P W}}{p_{P W}+p_{R W}}\right) .
$$

Since blacks are on average poorer, the right hand side is positive and we can therefore divide both sides by the expression on the right hand side so that the condition simplifies to

$$
\left(\frac{p_{P B}}{p_{P B}+p_{R B}}+\frac{p_{P W}}{p_{P W}+p_{R W}}\right)>1
$$

Since $p_{P B} /\left(p_{P B}+p_{R B}\right)>p_{P W} /\left(p_{P W}+p_{R W}\right)$, we can write $p_{P B} /\left(p_{P B}+p_{R B}\right)=p_{P W} /$ $\left(p_{P W}+p_{R W}\right)+\varepsilon$ for some $\varepsilon>0$. Hence, we need to show that $p_{P W} /\left(p_{P W}+p_{R W}\right)>$ $(1-\varepsilon) / 2$. The assumption that poor are in majority implies

$$
\frac{p_{P B}}{p_{P B}+p_{R B}}\left(p_{P B}+p_{R B}\right)+\frac{p_{P W}}{p_{P W}+p_{R W}}\left(p_{P W}+p_{R W}\right)>\frac{1}{2} .
$$

Substituting $p_{P B} /\left(p_{P B}+p_{R B}\right)$ we can write this condition as

$$
\left(\frac{p_{P W}}{p_{P W}+p_{R W}}+\varepsilon\right)\left(p_{P B}+p_{R B}\right)+\frac{p_{P W}}{p_{P W}+p_{R W}}\left(1-p_{P B}-p_{R B}\right)>\frac{1}{2},
$$

which can be further rewritten as

$$
\frac{p_{P W}}{p_{P W}+p_{R W}}>\frac{1-2\left(p_{P B}+p_{R B}\right) \varepsilon}{2} .
$$


Since $\left(p_{P B}+p_{R B}\right)<1 / 2$, we have $\left(1-2\left(p_{P B}+p_{R B}\right) \varepsilon\right) / 2>(1-\varepsilon) / 2$, and we have therefore shown what we needed to show.

\section{A.6 Proof of Lemma 3}

When whites and blacks are equally rich, we can see from (4) and (5) that the rich will always prefer zero taxes irrespective of how they identify themselves. Poor identifying with their ethnic identities will prefer the tax rate $1-\left(y_{P}+\gamma y\right) /(1+\gamma) y$ whereas poor identifying with their class will prefer the tax rate $1-y_{P} / y$. Since the poor are in majority, the median tax rate will be either of these two tax rates. The remainder of the result follows directly from the assumptions that the poor are in majority, blacks are in minority and poor whites are in minority.

\section{A.7 Proof of Proposition 3}

Let $p_{B}$ denote the proportion of poor and $p_{P}$ the proportion of rich. Since whites and blacks are equally rich, $p_{P B}=p_{P} p_{B}, p_{R B}=\left(1-p_{P}\right) p_{B}, p_{P W}=p_{P}\left(1-p_{B}\right)$ and $p_{R W}=$ $\left(1-p_{P}\right)\left(1-p_{B}\right)$. Using these relations the two conditions for ethnic identification (A3) and (A4) can be rewritten as

$$
\begin{gathered}
P B: \frac{1-p_{B}}{1-p_{P}}>\frac{1}{\beta}\left(\alpha-\frac{\gamma}{\delta}(1-t)\left(y_{R}-y_{P}\right)\right), \\
P W: \frac{p_{B}}{1-p_{P}}>\frac{1}{\beta}\left(\alpha-\frac{\gamma}{\delta}(1-t)\left(y_{R}-y_{P}\right)\right) .
\end{gathered}
$$

Since whites and blacks both have the average income $y$ and the average income of both ethnic groups is unchanged, the median tax rates for given identities and the status of different identities remain unchanged.

First suppose that poor whites initially identify as white so that the tax rate is $t_{P W W}^{*}=$ $t_{P B B}^{*}$ (according to Lemma 3). An increase of $p_{B}$ implies that the left hand side of the identity choice inequality for poor whites increases which in turn implies that identity choices and hence the tax rate will remain unchanged. This is true both irrespective of whether poor whites are in majority or not.

Now suppose instead that poor whites are in minority and that both poor blacks and poor whites identify as poor so that the equilibrium tax rate is $t_{P W P}^{*}=t_{P B P}^{*}$. An increase in $p_{B}$ will then decrease the left hand side of the identity choice inequality for poor blacks which implies that they will not change their identity. Since the right hand side is the same for both poor blacks and poor whites and $p_{B}<1 / 2$, poor whites will never identify as white unless the poor black identify as black and so the tax rate remains unchanged. 
Finally, suppose that poor whites are in minority, poor whites identify as poor and poor blacks identify as black so that the tax rate is $t_{P W W}^{*}=t_{P B B}^{*}$. Increasing $p_{B}$ might then induce the poor blacks to switch to the poor identity so that the tax rate will be $t_{P W P}^{*}=t_{P B P}^{*}$. Alternatively, poor whites may switch to the white identity, but that would leave the tax rate unaffected (recall that Lemma 2 implies that not both black and white can switch identities in this case). If instead poor whites are in majority and initially identify as poor, the tax rate is $t_{P W P}^{*}=t_{P B P}^{*}$ and an increase in $p_{B}$ might induce them to shift to the white identity, resulting in the low tax rate $t_{P W W}^{*}=t_{P B B}^{*}$.

\section{A.8 Proof of Proposition 4}

As income inequality changes, the only thing that changes in the conditions for ethnic identification (A1) and (A2) is the term $(1-t)\left(y_{R}-y_{P}\right)$ which reflects the relative status of the ethnic identity over the poor identity. Since blacks and whites are equally rich, there are only two tax rates in equilibrium: $t_{P W W}^{*}=t_{P B B}^{*}=1-\left(y_{P}+\gamma y\right) /(1+\gamma) y$ and $t_{P W P}^{*}=t_{P B P}^{*}=1-y_{P} / y$. Clearly, both these tax rates increase with income inequality for given identity choices. Since both the tax rate and income inequality increase, the effect on relative status $(1-t)\left(y_{R}-y_{P}\right)$ is ambiguous.

Since we keep average income constant, i.e., $\partial y / \partial\left(y_{R}-y_{P}\right)=0$, it must hold that

$$
\frac{\partial y_{P}}{\partial\left(y_{R}-y_{P}\right)}=-\frac{1-p_{P}}{p_{P}} \frac{\partial y_{R}}{\partial\left(y_{R}-y_{P}\right)} .
$$

It is the case that $\partial\left(y_{R}-y_{P}\right) / \partial\left(y_{R}-y_{P}\right)=1$ and this implies that

$$
\frac{\partial y_{R}}{\partial\left(y_{R}-y_{P}\right)}-\frac{\partial y_{P}}{\partial\left(y_{R}-y_{P}\right)}=1
$$

Combining these two observations we get

$$
\frac{\partial y_{P}}{\partial\left(y_{R}-y_{P}\right)}=-\left(1-p_{P}\right) \text { and } \frac{\partial y_{R}}{\partial\left(y_{R}-y_{P}\right)}=p_{P}
$$

Now consider the case when poor blacks identify as black (and perhaps poor whites identify as white). For given identity choices, the tax rate increases. If poor blacks switch to the poor identity, then the tax rate increases further. To see if this can happen, note that the 
effect on relative status of higher income inequality is given by

$$
\begin{aligned}
\frac{\partial\left(1-t_{P B B}^{*}\right)\left(y_{R}-y_{P}\right)}{\partial\left(y_{R}-y_{P}\right)} & =\left(1-t_{P B B}^{*}\right)-\frac{\partial t_{P B B}^{*}}{\partial\left(y_{R}-y_{P}\right)}\left(y_{R}-y_{P}\right) \\
& =\frac{y_{P}+\gamma y}{(1+\gamma) y}-\frac{1-p_{P}}{(1+\gamma) y}\left(y_{R}-y_{P}\right) .
\end{aligned}
$$

Rearranging the latter expression shows that relative status is increasing in income inequality if and only if $y_{P} / y>(1-\gamma) / 2$. If this condition is satisfied, then the identity choice of poor blacks remain unchanged. Otherwise, poor blacks might switch to the poor identity. From Lemma 2 we also know that if poor blacks switch to the poor identity, then poor whites will switch to the poor identity as well (unless they already identified as poor)

Now consider the case when both poor blacks and poor whites identify as poor. In this case, the effect on relative status is given by

$$
\begin{aligned}
\frac{\partial\left(1-t_{P B P}^{*}\right)\left(y_{R}-y_{P}\right)}{\partial\left(y_{R}-y_{P}\right)} & =\left(1-t_{P B P}^{*}\right)-\frac{\partial t_{P B P}^{*}}{\partial\left(y_{R}-y_{P}\right)}\left(y_{R}-y_{P}\right) \\
& =\frac{y_{P}}{y}-\frac{1}{y}\left(1-p_{P}\right)\left(y_{R}-y_{P}\right) .
\end{aligned}
$$

This is increasing if $y_{P} / y>1 / 2$. Note that if this condition holds, then relative status at the ethnic tax rate is increasing for all values of $\gamma$. If $y_{P} / y>1 / 2$, then poor blacks (and possibly poor whites) might switch to ethnic identities, implying that the net effect on the tax rate is ambiguous. However, if $y_{P} / y<1 / 2$, identity choices remain unchanged and the tax rate will increase. 


\section{Appendix B: Interethnic Income Inequality}

In this Appendix, we analyze the case when there is interethnic income inequality in the sense that the ethnic majority group (whites) are on average richer than the ethnic minority group (blacks). Proposition B1 considers an increase in ethnic diversity when there is interethnic inequality. Proposition B2 considers an inflow of poor blacks, which changes both ethnic diversity and interethnic income inequality. Proposition B3 considers an increase in interethnic income inequality when ethnic diversity is held constant. Before we proceed, Lemma B1 (which corresponds to Lemma 3 in the main text) gives the feasible equilibrium tax rates.

If white people are richer than black people, poor whites and poor blacks prefer different tax rates when they identify with their ethnic group. There can thus be three different tax rates in equilibrium. We refer to these as the poor $\left(t_{P W P}^{*}=t_{P B P}^{*}\right)$, black $\left(t_{P B B}^{*}\right)$ and white $\left(t_{P W W}^{*}\right)$ tax rates.

Lemma B1 If whites are on average richer than blacks and poor whites are in minority, then there are three feasible median tax rates in equilibrium:

1. If poor whites identify as white the equilibrium tax rate will be the white tax rate $\left(t_{P W W}^{*}=1-\left(y_{P}+\gamma y_{W}\right) /(1+\gamma) y\right)$.

2. If poor whites and poor blacks identify as poor the equilibrium tax rate will be the poor tax rate $\left(t_{P B P}^{*}=t_{P W P}^{*}=1-y_{P} / y\right)$.

3. If poor whites identify as poor, but poor blacks as black, the equilibrium tax rate will be the black tax rate $\left(t_{P B B}^{*}=1-\left(y_{P}+\gamma y_{B}\right) /(1+\gamma) y\right)$.

Proof. We know from Lemma 1 that the assumption that whites are richer than blacks imply that $t_{R W W}^{*} \leq t_{R B B}^{*}$ and $t_{P W W}^{*} \leq t_{P B B}^{*}$. Combining this with the first part of Lemma 1 , we see that optimal tax rates can be ordered in two different ways depending on $t_{R B B}^{*}$ and $t_{P W W}^{*}$ :

$$
0=t_{R B R}^{*}=t_{R W R}^{*} \leq t_{R W W}^{*} \leq\left[\begin{array}{c}
t_{R B B}^{*} \leq t_{P W W}^{*} \\
\text { or } t_{P W W}^{*} \leq t_{R B B}^{*}
\end{array}\right] \leq t_{P B B}^{*} \leq t_{P W P}^{*}=t_{P B P}^{*}=1-\frac{y_{P}}{y}
$$

First suppose that poor whites identify as white. From the inequalities above we see that this implies that rich whites prefer lower tax rates and poor blacks prefer higher taxes than poor whites. Suppose that $t_{R B B}^{*} \leq t_{P W W}^{*}$ so that rich blacks always prefer a lower tax rate than poor whites. Since the poor are in majority and poor white are in minority, the median tax rate must be $t_{P W W}^{*}, t_{P B B}^{*}$ or $t_{P B P}^{*}=t_{P W P}^{*}$, but since $t_{R B B}^{*} \leq t_{P W W}^{*} \leq t_{P B B}^{*} \leq$ 
$t_{P B P}^{*}=t_{P W P}^{*}$, the median must be $t_{P W W}^{*}$. If we instead assume that $t_{P W W}^{*} \leq t_{R B B}^{*}$, then rich blacks may prefer a higher tax rate than poor whites. However, since we have assumed that blacks are in minority the median tax rate must be $t_{P W W}^{*}$ also in this case.

Now suppose instead that the poor whites identify as poor. Since the poor are in majority and poor whites are in minority, the median tax rate will be either $t_{P B B}^{*}$ or $t_{P W P}^{*}=t_{P B P}^{*}$. Therefore the median tax rate will be $t_{P B B}^{*}$ if poor blacks identify as black and $t_{P W P}^{*}=t_{P B P}^{*}$ if poor blacks identify as poor.

Proposition 3 applies to the case when blacks and whites have the same income. When the minority population is poorer than the majority group, increasing the size of the minority group decreases the average income in the population, leading to lower tax rates for given identity choices. ${ }^{41}$ Proposition B1 focuses on the case when blacks are on average poorer and poor whites are in minority, but the number of blacks increases proportionally so that the average income of both blacks and whites are held constant. In this case, the result is very similar to Proposition 3.

Proposition B1 If poor whites are in minority and whites are on average richer than blacks, then an increase in the black population, while keeping the average income of blacks and whites constant, implies the following for the equilibrium tax rate:

1. If poor whites initially identify as white or both poor whites and poor blacks identify as poor, the equilibrium tax rate decreases.

2. If poor whites initially identify as poor and poor blacks identify as black, then either poor blacks or poor whites may switch identity and the equilibrium tax rate may therefore either increase or decrease.

Proof. Denote the proportion of blacks by $p_{B}$, the proportion of poor among the blacks as $p_{P \mid B}$ and the proportion of poor among whites as $p_{P \mid W}$. This implies that $p_{P B}=p_{P \mid B} p_{B}$, $p_{R B}=\left(1-p_{P \mid B}\right) p_{B}, p_{P W}=p_{P \mid W}\left(1-p_{B}\right)$ and $p_{R W}=\left(1-p_{P \mid W}\right)\left(1-p_{B}\right)$. To see how identity choices are affected, we use these relations to rewrite the inequalities (A3) and (A4) as

$$
\begin{gathered}
P B: \frac{p_{P \mid W}}{\left(p_{P \mid B}\left(\frac{p_{B}}{1-p_{B}}\right)+p_{P \mid W}\right)\left(1-p_{P \mid B}\right)}>\frac{1}{\beta}\left(\alpha-\frac{\gamma}{\delta}(1-t)\left(y_{R}-y_{P}\right)\right), \\
P W: \frac{p_{P \mid B}}{\left(p_{P \mid B}+p_{P \mid W}\left(\frac{1-p_{B}}{p_{B}}\right)\right)\left(1-p_{P \mid W}\right)}>\frac{1}{\beta}\left(\alpha-\frac{\gamma}{\delta}(1-t)\left(y_{R}-y_{P}\right)\right) .
\end{gathered}
$$

\footnotetext{
${ }^{41}$ This is a result of the fact that there are only two income groups in the population - with continuous incomes both the median and average income would typically decrease and the overall effect be ambiguous.
} 
We see that, for a given tax rate, the poor identity becomes more attractive for poor blacks as the proportion of blacks increases, whereas the white identity becomes more attractive for poor whites.

Since we increase the proportion of blacks but keep the average income of blacks and whites constant, the average income in the population decreases, implying lower optimal tax rates for given identities. This makes the ethnic identities more attractive for both poor blacks and poor whites.

If poor whites initially identify as white, the tax rate is $t_{P W W}^{*}$. More blacks will both decrease the tax rate and make the left hand side of the inequality for poor whites higher, which implies that poor whites will continue to identify as white and the tax rate will remain at $t_{P W W}^{*}$.

If poor blacks and poor whites identify as poor, the median tax rate is $t_{P B P}^{*}=t_{P W P}^{*}$. Since the tax rate decreases, we cannot be certain that poor blacks will continue to identify as poor. If poor blacks switch to the black identity, poor whites may switch to the white identity. In all these different cases, the end effect till be a decrease in the tax rate.

If poor whites initially identify as poor, but poor blacks as black, the median tax rate will be $t_{P B B}^{*}$. For given identity choices, the tax rate decreases. Poor black may switch to the poor identity when the proportion of blacks increases, whereas poor whites may switch to the white identity. However, both poor blacks and poor whites cannot change identities since poor blacks identify as black whenever poor whites identify as white. The end effect is therefore not clear in this case.

Proposition B1 is illustrated by a parametric example in Figure B1 where we only consider the case when poor whites are in minority. ${ }^{42}$ One difference compared to the previous parametric examples in Figure 1 and Figure 2 is that since the average income decreases in ethnic diversity, tax rates for given identity choices are decreasing in the proportion of blacks. In this example, poor blacks identify as black irrespective of the tax rate. Poor whites identify as poor when the proportion of blacks is below 20 percent. If there are sufficiently many blacks for poor whites to be in minority (17 percent), the equilibrium tax rate is therefore the black tax rate. When the proportion of blacks is between 20 and 38 percent, poor whites still identify as poor at the black tax rate, but as white at the white tax rate, implying that we have multiple equilibria. As the tax rate increases above 38 percent, poor whites identify as white also at the black tax rate, and so only the white tax rate is an equilibrium.

\footnotetext{
${ }^{42}$ The parameters used in this example are $p_{P \mid B}=0.8, p_{P \mid W}=0.6, y_{P}=100, y_{R}=300, \gamma=0.5$, $\delta=20, \alpha=4$ and $\beta=0.5$. These parameters imply that the average income of the white group is 29 percent higher than the average income of the black group, which is lower than the actual income difference between blacks and whites in the US.
} 


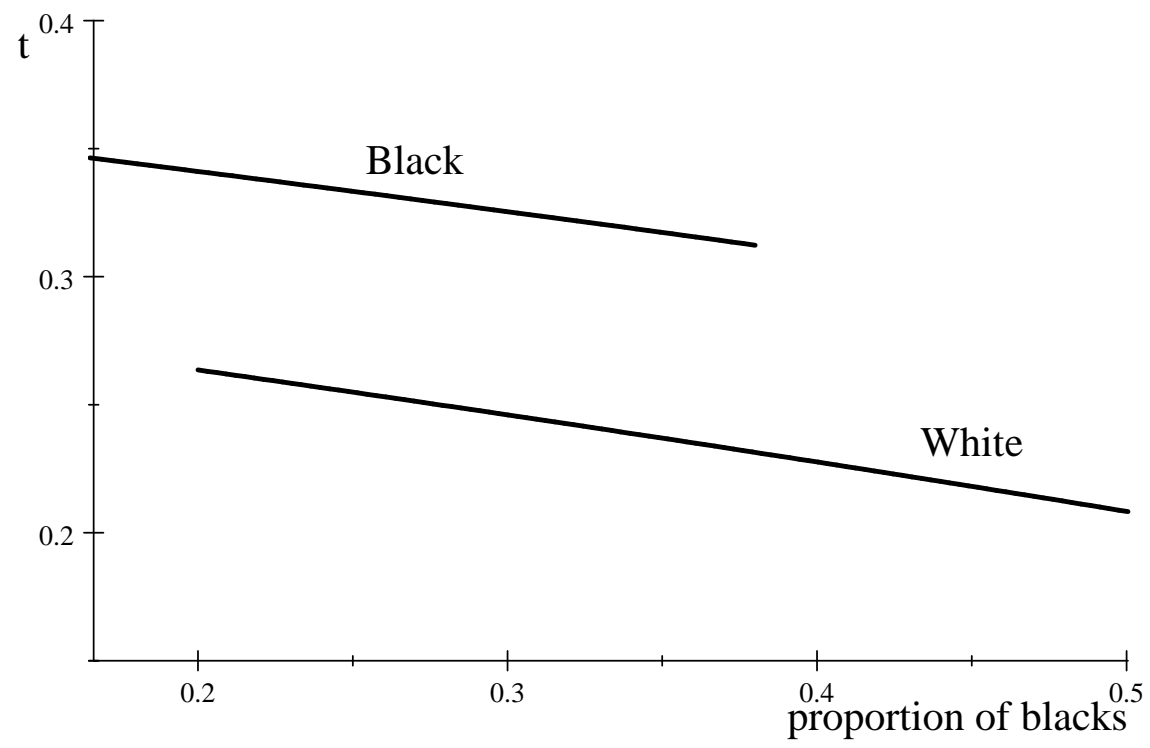

Figure B1. Increase in ethnic diversity (interethnic income inequality)

In both Proposition 3 and B1, the number of poor blacks and rich blacks increases proportionally, ensuring that the incomes of the black and white groups are held constant. In many cases, for example immigration, it is more reasonable to assume that it is only the proportion of poor blacks that increases. This implies a change in income inequality both within and between the two ethnic groups, which introduces a more intricate interaction between social class and ethnicity.

Proposition B2 establishes what can be said generally when the proportion of blacks among the poor increases and the average income in the population is held constant. ${ }^{43}$ As the number of blacks among the poor increases, the white group becomes richer and the status of the white identity increases. Since there are more poor blacks in the population, the distance to the poor identity increases for poor whites. These two effects tend to push poor whites toward the white identity, but are counteracted by the increase in the cognitive distance to the white group (since the proportion of poor whites among whites goes down). As the proportion of poor whites among whites decreases at a faster rate the lower is the initial proportion of poor whites, the latter effect dominates if there are sufficiently many blacks among the poor. The exact threshold level $\left(\bar{p}_{B \mid P}\right)$ is specific to our linear specification of the cognitive distance function, but, as can be seen from Proposition

\footnotetext{
${ }^{43}$ The main reason for holding the average income constant is that the comparative statics become considerably more complicated if also the average income changes. In addition, decreasing the average income have an unambigous negative effect on the tax level, but this result is an artefact of the fact that their are only two income groups (otherwise both the median and average would change).
} 
$\mathrm{B} 2$, it is increasing in the proportion of rich whites to the poor.

Similarly, the effect of more blacks among the poor on the identity of poor blacks is not guaranteed to go in the direction of class identification. On the one hand, both the status of the black group and the distance to the poor identity decreases, but on the other hand the distance to the black identity decreases since the black group now consists of relatively more poor blacks. ${ }^{4}$ The latter effect dominates as long as the proportion of blacks among the poor is below a certain threshold $\left(\hat{p}_{B \mid P}\right)$. This suggests that if the size of a small minority group is increased with poor people, it might push the poor of the minority group toward ethnic identification.

Proposition B2 If poor whites are in minority and whites are on average richer than blacks, then an increase of blacks among the poor $\left(p_{B \mid P}\right)$, while the average population income is held constant, implies the following for the equilibrium tax rate:

1. If poor whites initially identify as white and the proportion of blacks among the poor is sufficiently low $\left(p_{B \mid P}<\bar{p}_{B \mid P}\right)$, then the equilibrium tax rate decreases and identity choices of poor whites are unchanged.

2. If both poor whites and poor blacks initially identify as poor and the proportion of blacks among the poor is sufficiently low $\left(p_{B \mid P}<\hat{p}_{B \mid P}\right)$, then poor blacks (and possibly also poor whites) may switch to the ethnic identity which decreases the tax rate.

3. If poor whites identify as poor and poor blacks as black and the proportion of blacks among the poor is sufficiently high $\left(p_{B \mid P}>\bar{p}_{B \mid P}\right)$, then the equilibrium tax rate will increase and poor blacks may switch to the poor identity which increases the tax rate further.

The threshold $\bar{p}_{B \mid P}$ is given by $1 / 2+p_{R W} / 2\left(p_{P B}+p_{P W}\right)$ and the threshold $\hat{p}_{B \mid P}$ is given by $1 / 2-p_{R B} /\left(p_{P B}+p_{P W}\right)$.

Proof. Denote the proportion of poor by $p_{P}$, the proportion of blacks among the poor by $p_{B \mid P}$ and the proportion of blacks among the rich by $p_{B \mid R}$. Then $p_{P B}=p_{B \mid P} p_{P}$, $p_{R B}=p_{B \mid R}\left(1-p_{P}\right), p_{P W}=\left(1-p_{B \mid P}\right) p_{P}$ and $p_{R W}=\left(1-p_{B \mid R}\right)\left(1-p_{P}\right)$. Using these relations we can rewrite the conditions for ethnic identification (A3) and (A4) as

$$
\begin{gathered}
P B:\left(1-p_{B \mid P}\right)\left(1+\frac{p_{B \mid P} p_{P}}{p_{B \mid R}\left(1-p_{P}\right)}\right)>\frac{1}{\beta}\left(\alpha-\frac{\gamma}{\delta}(1-t)\left(y_{R}-y_{P}\right)\right), \\
P W: p_{B \mid P}\left(1+\frac{\left(1-p_{B \mid P}\right) p_{P}}{\left(1-p_{B \mid R}\right)\left(1-p_{P}\right)}\right)>\frac{1}{\beta}\left(\alpha-\frac{\gamma}{\delta}(1-t)\left(y_{R}-y_{P}\right)\right) .
\end{gathered}
$$

\footnotetext{
${ }^{44}$ Similarly, the status gain of choosing an ethnic identity goes down, and the sign of the total effect on the identity choice depends on the relative importance of status and class hostility.
} 
By differentiating the left hand sides with respect to $p_{B \mid P}$ we see that the left hand sides of these inequalities are increasing in $p_{B \mid P}$ if the following holds:

$$
\begin{gathered}
P B: p_{B \mid P}<\frac{p_{P}-\left(1-p_{P}\right) p_{B \mid R}}{2 p_{P}}=\hat{p}_{B \mid P}, \\
P W: p_{B \mid P}<\frac{1-\left(1-p_{P}\right) p_{B \mid R}}{2 p_{P}}=\bar{p}_{B \mid P} .
\end{gathered}
$$

Note that these thresholds satisfy $\hat{p}_{B \mid P}<1 / 2<\bar{p}_{B \mid P}$.

An increase in $p_{B \mid P}$ implies that average income in the population is unchanged, whereas the income of the black group decreases and the income of the white group increases. This implies that $t_{P W W}^{*}$ decreases and $t_{P B B}^{*}$ increases, while $t_{P B P}^{*}=t_{P W P}^{*}$ is unaffected.

First suppose that poor whites initially identify as white, and consequently poor blacks identify as black, so that the median tax is $t_{P W W}^{*}$. Then the right hand side of the identity choices is decreasing in $p_{B \mid P}$, so we can be certain that poor whites continue to identify as white if the left hand side is increasing, i.e., if $p_{B \mid P}<\bar{p}_{B \mid P}$. If this condition is not satisfied, we cannot say what happens to the identity choice of poor whites and therefore not what happens to the tax rate either.

Now suppose that both poor whites and poor blacks identify as poor. This implies that the tax rate is $t_{P B P}^{*}=t_{P W P}^{*}$, which is unaffected by an increase in $p_{B \mid P}$ so that the right hand sides above are constant. If $p_{B \mid P}<\hat{p}_{B \mid P}$, then poor blacks (and possibly also poor whites since $\left.\hat{p}_{B \mid P}<\bar{p}_{B \mid P}\right)$ might switch to the ethnic identity. In all cases, this means that the tax rate may decrease if poor blacks (and possibly also poor whites) switch identities.

Finally, suppose that poor whites identify as poor and poor blacks as black so that the tax rate is $t_{P B B}^{*}$. This tax rate is increasing in $p_{B \mid P}$, so the right hand sides of the conditions for ethnic identification increases, which makes the poor identity more attractive. If $p_{B \mid P}>\bar{p}_{B \mid P}$, then the left hand sides are decreasing and poor blacks might switch to the poor identity while poor whites continue to identify as poor. In this case, the tax rate will increase, whereas we cannot tell what will happen if $p_{B \mid P}<\bar{p}_{B \mid P}$.

In order to demonstrate some of the different effects summarized in Proposition B2, we again use a simple parametric example. ${ }^{45}$ As can be seen from Figure B2, the black tax rate is increasing and the white tax rates is decreasing in the proportion of blacks among the poor. The reason is that the average income of the black group decreases, while the average income of the white group increases.

First, consider the case when there are 20 to 27 percent blacks among the poor. In this case, the poor whites identify as poor at all tax rates, whereas poor blacks only identify

\footnotetext{
${ }^{45}$ The parameters used in this example are $p_{B \mid R}=0.2, p_{P}=0.55, y_{P}=100, y_{R}=300, \gamma=0.5, \delta=20$, $\alpha=4$ and $\beta=0.7$.
} 
as poor if the highest tax rate prevails. This implies that the highest tax rate is an equilibrium. However, since poor blacks identify as black at the black tax rate, this can also be an equilibrium. As the number of blacks among the poor increases slightly, but not above 35 percent, poor blacks identify as black and poor whites as poor at all tax three tax rates, so the black tax rate is the only possible equilibrium. This demonstrates that an increase of low-skilled workers from a minority group might push these workers toward ethnic identification and lower tax rates. Hence, whereas Proposition 3 and B1 showed that increasing ethnic diversity may induce the poor from a minority group to identify with their social class instead of their ethnic group, this result might be overturned when the minority group also becomes poorer. In other words, lower redistribution as a result of ethnic diversity might be driven by the demands of the poor minority group.

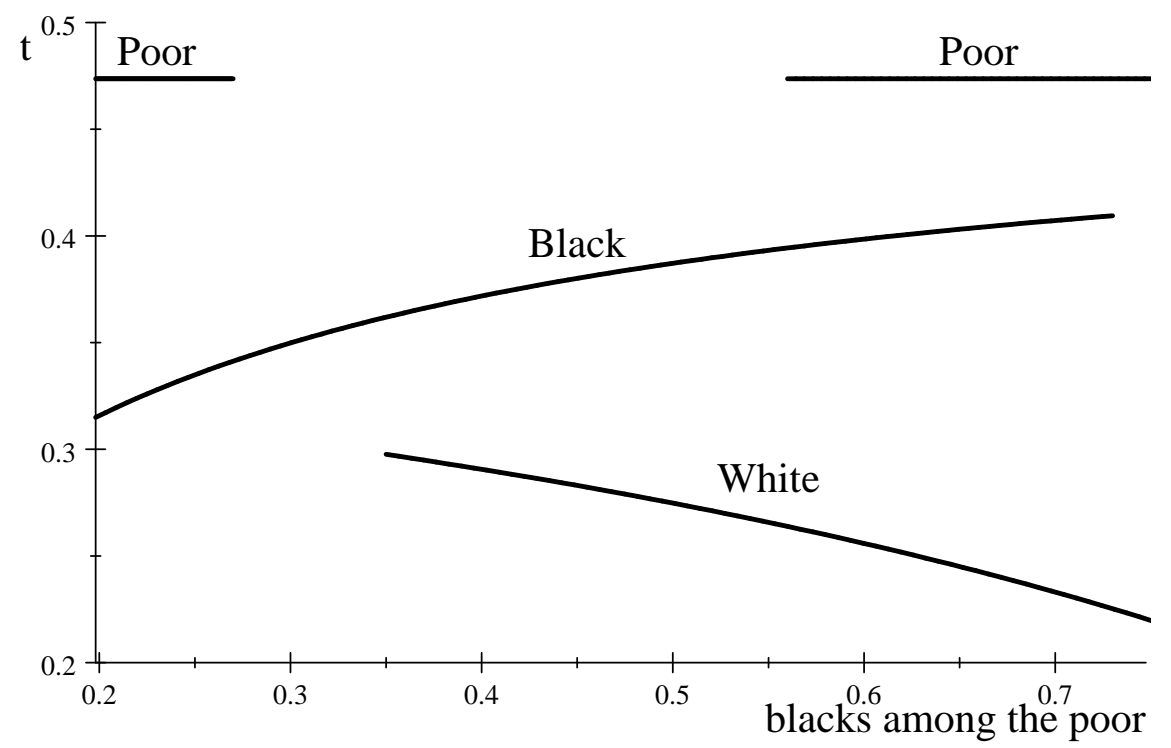

Figure B2. Increase in the proportion of blacks among the poor

When the number of blacks among the poor is between 35 and 56 percent, poor whites identify as white at the white tax rate, but as poor at higher tax rates. Poor blacks identify as black at all tax rates, so both the white and black tax rates are equilibria. In the interval between 56 and 73 percent blacks among the poor, poor whites identify as white at the white tax rate, but as poor at the black and poor tax rate, whereas poor blacks identify as black at the white and black tax rates. This implies that all three tax rates are equilibria. Finally, when the number of blacks among the poor is above 73 percent, but not so many that blacks are in majority, poor blacks identify as poor at the black tax rate so that there are again two equilibria - either the poor or the white tax rate. 
The example in Figure B2 illustrates that identity choices of one group may depend on the identity choices of another group. When there are 56 to 73 percent blacks among the poor, poor blacks identify as black if poor whites identify as white. However, if poor whites instead identify as poor, poor blacks might identify as poor. When there are more than 73 percent blacks among the poor, poor blacks identify as poor for certain if poor whites identify as poor, whereas they identify as black if poor whites identify as white.

In this example, the high tax equilibrium where both poor blacks and poor whites identify as poor is only possible for a very low and a very high degree of ethnic diversity, whereas it is not possible for intermediate levels of diversity (i.e., between 27 and 56 percent of blacks among the poor).

As discussed in Section 5, it is often argued that higher pre-tax income inequality increases the support for redistribution. In contrast, Lind (2007) argues that interethnic inequality reduces redistribution. ${ }^{46}$ To study this effect in our model, we model income inequality between blacks and whites as an increase in the proportion of poor among blacks and a corresponding decrease in the number of poor among whites, while the total number of poor and blacks is held constant. ${ }^{47}$ This change clearly decreases the status of the black identity, whereas the status of the white identity increases. Cognitive distances to both ethnic and class identities are affected. For poor blacks, the distances to the black and poor identities shrink since there are more poor blacks among the black, but also more poor blacks among the poor. For the same reasons the opposite holds for poor whites - the distances to the white and poor identities increase. In addition, ethnic tax rates are also affected since blacks become poorer and whites become richer. Proposition B3 establishes the different cases when the net effect on the tax rate can be established.

Proposition B3 If poor whites are in minority and blacks are on average poorer than whites, then an increase in the proportion of poor among blacks, holding average income and the proportion of blacks constant, implies the following for the equilibrium tax rate:

1. If poor whites identify as white and there are fewer blacks than rich people, then the tax rate decreases (and identity choices of poor whites are unaffected).

2. If poor whites and poor blacks identify as poor, then poor blacks (and possibly poor whites if there are fewer blacks than rich people) may switch to ethnic identities which decreases the tax rate.

\footnotetext{
${ }^{46}$ Lind (2007) shows this theoretically in a model where people's altruism are targeted towards their own group. He also provides somewhat weak empirial support that between group inequality reduces the support for redistribution (using U.S. panel data from 1969 to 2000).

${ }^{47}$ Studying interethnic inequality in this way implies that the cognitive distances are affected, whereas these are unaffected by a change in standard income inequality. In a model with more than two income groups, interethnic inequality could instead be analyzed as income changes that would not affect cognitive distances.
} 


\section{If poor whites identify as poor, poor blacks as black and there are more blacks than rich} people, then the tax rate increases and poor blacks might switch to the poor identity which increases the tax rate further.

Proof. Let $p_{P}$ denote the proportion of poor in the population, $p_{B}$ the proportion of blacks and $p_{P \mid B}$ the proportion of poor among blacks. This implies that $p_{P B}=p_{P \mid B} p_{B}$, $p_{R B}=\left(1-p_{P \mid B}\right) p_{B}, p_{P W}=p_{P}-p_{P \mid B} p_{B}$ and $p_{R W}=\left(1-p_{B}\right)-p_{P}+p_{P \mid B} p_{B}$. Using these relations we can rewrite the conditions for ethnic identification (A3) and (A4) as

$$
\begin{aligned}
P B & : \frac{p_{P}-p_{P \mid B} p_{B}}{\left(1-p_{P \mid B}\right) p_{P}}>\frac{1}{\beta}\left(\alpha-\frac{\gamma}{\delta}(1-t)\left(y_{R}-y_{P}\right)\right) \\
P W & : \frac{p_{P \mid B} p_{B}\left(1-p_{B}\right)}{\left(1-p_{B}-p_{P}+p_{P \mid B} p_{B}\right) p_{P}}>\frac{1}{\beta}\left(\alpha-\frac{\gamma}{\delta}(1-t)\left(y_{R}-y_{P}\right)\right) .
\end{aligned}
$$

The left hand side for poor blacks is always increasing in $p_{P \mid B}$ whereas the left hand side for poor whites is increasing if $p_{B}<1-p_{P}$.

Although the average income in the population is constant when $p_{P \mid B}$ increases, the income of the black group falls and the income of the white group increases. This implies that $t_{P B B}^{*}$ increases for given identity choices, $t_{P W W}^{*}$ decreases and the tax rate associated with the poor identity is unchanged.

First suppose that poor whites identify as white (and thereby poor blacks identify as black). The tax rate is $t_{P W W}^{*}$ which is decreasing in $p_{P \mid B}$. As long as $p_{B}<1-p_{P}$, the poor whites will continue to identify as white. If this is not satisfied, they may change to the poor identity, and the end effect on the tax rate is unclear.

Now suppose that poor whites and poor blacks identify as poor so that the tax rate does not change as a response to an increase in $p_{P \mid B}$. Then poor blacks may switch to a black identity implying a lower tax rate, and if $p_{B}<1-p_{P}$ poor whites may switch to the white identity.

Finally, suppose that poor blacks identify as black and poor whites as poor. Then the tax rate is increasing in $p_{P \mid B}$ for given identity choices. Poor blacks may therefore switch to the poor identity, which would increase the tax rate. In order to be certain that poor whites do not switch identity, we must assume that $p_{B}>1-p_{P}$.

As shown by the proof of Proposition B3, poor blacks become more likely to identify as black when the number of poor among blacks increases (for a given tax rate). This is a result of the linear specification of cognitive distances - the shorter distance to the black identity turns out to always dominate the effect of lower status of the black identity and shorter distance to the poor identity. For poor whites, the net effect depends on the proportion of blacks to the proportion of rich. The status of the white identity increases, 
but the distances to both the poor identity and to the white identity increase. If there are fewer blacks than rich in the population, it is certain that poor whites become more likely to identify as white.

Comparing Proposition 4 and B3, it is clear that the effects of standard versus interethnic income inequality typically have opposite effects if income inequality is initially high and the proportion of blacks is lower than the proportion of rich people. This is in line with the theoretical and empirical results in Lind (2007). The novel idea behind our result is that higher income inequality between ethnic groups might induce the poor of the majority group to switch to their ethnic identity in order to enjoy the higher status of the ethnic group. 


\section{Appendix C: Continuous Income}

In this Appendix, we extend the black and white model with income heterogeneity within social classes.

Let there be a continuum of agents that are endowed with pre-tax income $y_{i}>0$ and let the pre-tax income of blacks and whites be given by the cumulative income distributions $B\left(y_{i}\right)$ and $W\left(y_{i}\right)$, both with support $\left(0, \max \left\{y_{i}\right\}\right]$. The distribution of income in the whole population is given by

$$
F\left(y_{i}\right)=p_{B} B\left(y_{i}\right)+\left(1-p_{B}\right) W\left(y_{i}\right),
$$

where $p_{B}<0.5$ is the proportion of blacks in the population. Let $y$ denote the average pre-tax income in the population, and let the average income of the four different social categories be denoted by $y_{B}, y_{W}, y_{P}$ and $y_{R}$. As in the standard black and white model, the poor are defined as those with pre-tax income below the average income, and we assume that they are in majority, i.e., $F(y)>0.5$.

All members of a particular type make the same identity choice. The right hand sides of the conditions for ethnic identification are the same as in (A1) and (A2) for poor whites and poor blacks, whereas the left hand sides depend on the average incomes of whites and blacks. Note that the assumptions made above imply that we can write the proportion of the four different types as $p_{P B}=p_{B} B(y), p_{R B}=p_{B}(1-B(y)), p_{P W}=\left(1-p_{B}\right) W(y)$ and $p_{R W}=\left(1-p_{B}\right)(1-W(y))$. Using these relations, we can rewrite the conditions for ethnic identification of poor blacks and poor whites, (A1) and (A2), as

$$
\begin{gathered}
P B:(1-t)\left(y_{B}-y_{P}\right)>\frac{\delta}{\gamma}\left(\alpha(1-B(y))-\beta \frac{\left(1-p_{B}\right) W(y)}{p_{B} B(y)+\left(1-p_{B}\right) W(y)}\right), \\
P W:(1-t)\left(y_{W}-y_{P}\right)>\frac{\delta}{\gamma}\left(\alpha(1-W(y))-\beta \frac{p_{B} B(y)}{p_{B} B(y)+\left(1-p_{B}\right) W(y)}\right) .
\end{gathered}
$$

Since the average incomes in the black and white groups can no longer been expressed as the proportion of different types in the population, these conditions cannot be simplified further. In particular, we cannot use Lemma 2 to rule out the case where poor blacks identify as poor and poor whites identify as white.

From the optimal tax rate (2) we know that the tax rate preferred by an agent with income $y_{i}$ identifying with group $j$ is given by

$$
t_{i, j}^{*}=\max \left\{1-\frac{1}{1+\gamma} \frac{y_{i}}{y}-\frac{\gamma}{1+\gamma} \frac{y_{j}}{y}, 0\right\}
$$

This implies that rich whites and rich blacks prefer zero tax rates when they identify as rich. In order to see how preferred taxes for the different types are related, note first that 
the slope with respect to individual income is always the same (unless the preferred tax rate is zero). Figure $\mathrm{C} 1$ shows preferred tax rates as a function of individual pre-tax income when $\gamma=2$, average income in the population is 5 and the average income of the white and black group is 6 and 3, respectively. The bold lines indicates the preferred tax rate when individuals identify with their ethnic group. The line with higher tax rates corresponds to the tax rates preferred by blacks. In this extended model, the average income of the poor might be higher or lower than the average income of blacks. Figure $\mathrm{C} 1$ therefore depict two different cases when the average income of the poor is 2.5 and 3.5. The dashed lines indicates the corresponding tax rates when the poor identify with the poor.

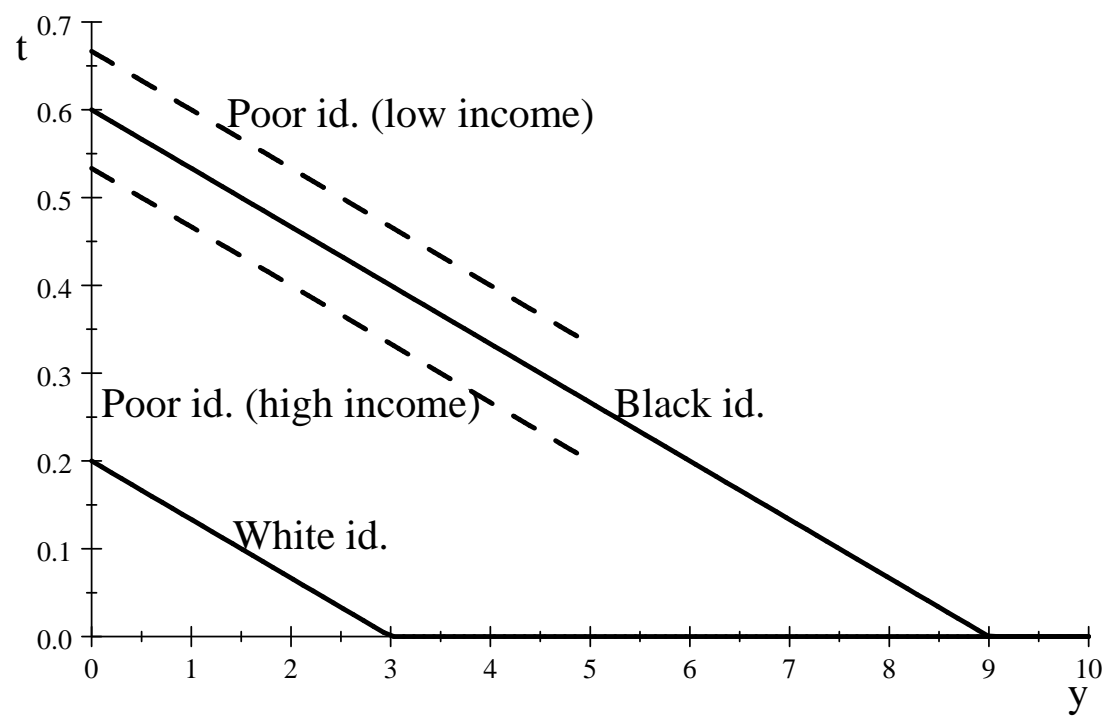

Figure C1. Preferred tax rates (interethnic income inequality)

It is clear from Figure $\mathrm{C} 1$ that rich blacks may prefer a higher tax rate than poor whites, implying that the identity choice of rich blacks must also be taken into account. Although this could be handled easily in the black and white model (see the proof of Lemma B1), it complicates the analysis of the extended model considerably. There are eight possible combinations of identity choices to take into account. For each of these combinations, there might be up to three median voters, which makes it tedious to solve for the equilibrium in the general case.

Because of this difficulty, we simplify by assuming that blacks and whites have the same average income, i.e., $y_{B}=y_{W}=y$, and that the proportion of poor is the same among blacks and whites, i.e., $B(y)=W(y)=F(y)$. Under these assumptions, the conditions 
for ethnic identification (C1) and (C2) simplify to

$$
\begin{aligned}
P B:(1-t)\left(y-y_{P}\right) & >\frac{\delta}{\gamma}\left(\alpha(1-F(y))-\beta\left(1-p_{B}\right)\right), \\
P W:(1-t)\left(y-y_{P}\right) & >\frac{\delta}{\gamma}\left(\alpha(1-F(y))-\beta p_{B}\right) .
\end{aligned}
$$

The left hand side is the same for both types, and the right hand side only differs in the cognitive distance to the poor identity. Since whites are in majority, the right hand side is always smaller for poor blacks than poor whites, i.e., whenever poor whites identify as white, poor blacks identify as black. Note that this would not be true if the proportion of poor within the two ethnic groups differed, i.e., if $B(y) \neq W(y)$.

Now consider optimal tax rates under these assumptions. The rich will always prefer zero taxes when identifying as rich, and poor blacks and whites prefer the same tax rate when they identify with their ethnic group for a given level of income. The preferred tax rates may look like in Figure $\mathrm{C} 2$.

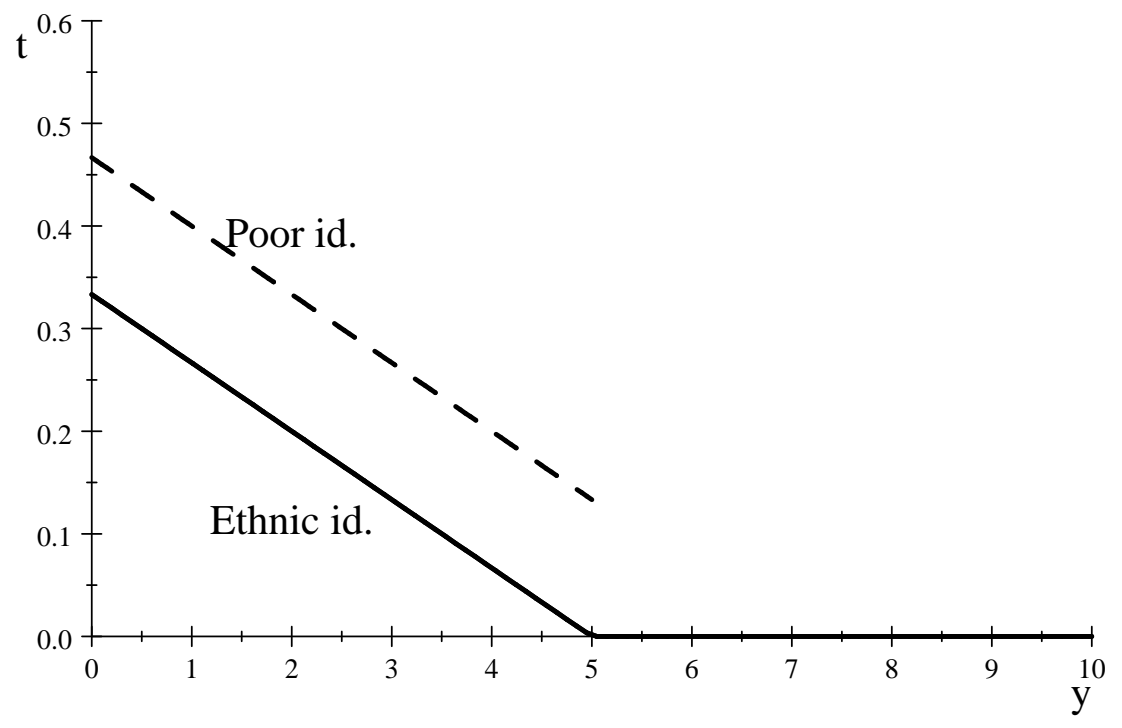

\section{Figure C2. Preferred tax rates (no interethnic income inequality)}

As can be seen from Figure $\mathrm{C} 2$ and optimal tax rate (C3), the poor always prefer positive taxes, whereas the rich always prefer zero taxes. Since the poor are in majority, this implies that the median voter (or voters) is poor and that the median tax is determined by the identity choices of the poor. Since poor blacks identify as black whenever poor whites identify as white, there are only three possible combinations of identity choices of the poor in equilibrium. Lemma $\mathrm{C} 1$ states these three combinations and the relation between the 
associated median tax rates.

Lemma C1 If whites and blacks have the same average income and proportion of poor, there are three potential equilibrium tax rates satisfying $t_{E}^{m}<t_{P E}^{m}<t_{P}^{m}$ :

1. If poor whites and poor blacks identify as poor, then the median tax rate is $t_{P}^{m}$.

2. If poor whites identify as poor and poor blacks as black, then the median tax rate is $t_{P E}^{m}$.

3. If poor whites identify as white, then the median tax rate is $t_{E}^{m}$.

Proof. Let the tax rate of poor blacks or poor whites when they identify with the poor be given by $t_{P}\left(y_{i}\right)$, and let $t_{E}\left(y_{i}\right)$ denote preferred taxes when they identify with their ethnic group. Using (C3) we can write these taxes as

$$
\begin{aligned}
& t_{P}\left(y_{i}\right)=1-\frac{1}{1+\gamma} \frac{y_{i}}{y}-\frac{\gamma}{1+\gamma} \frac{y_{P}}{y} \\
& t_{E}\left(y_{i}\right)=1-\frac{1}{1+\gamma} \frac{y_{i}}{y}-\frac{\gamma}{1+\gamma} .
\end{aligned}
$$

Note that these functions are continuous and decreasing in personal income. In order to determine the median tax, we need to determine the inverse of these two functions. The income corresponding to a certain optimal tax in the two cases are given by

$$
\begin{aligned}
& y_{i}\left(t_{P}\right)=(1+\gamma)\left(1-t_{P}\right) y-\gamma y_{P}, \\
& y_{i}\left(t_{E}\right)=(1+\gamma)\left(1-t_{E}\right) y-\gamma y .
\end{aligned}
$$

This allows us to define the median tax that will prevail for the three possible combinations of identity choices.

1. Both poor whites and poor blacks identify as poor. In this case, both poor blacks and poor whites prefer the tax given by $t_{P}\left(y_{i}\right)$. Since this function is decreasing in personal income, the median voters (one poor black and one poor white) are therefore given by the tax rate that gets support from exactly half of the population. In other words, the median tax is given by the tax rate $t_{P}^{m}$ that solves

$$
0.5=F\left((1+\gamma)\left(1-t_{P}^{m}\right) y-\gamma y_{P}\right)
$$

2. Poor whites identify as poor and poor blacks as black. In this case the preferred tax of poor blacks are given by the bold line in Figure A2, whereas the preferred taxes of 
poor whites is given by the dashed line. The median voter can either be poor white (if poor whites are in majority), poor black or there can be two median voters - one poor black and one poor white. The median tax is implicitly given by

$$
\begin{aligned}
0.5 & =p_{B} B\left(\max \left\{(1+\gamma)\left(1-t_{P E}^{m}\right) y-\gamma y, 0\right\}\right) \\
& +\left(1-p_{B}\right) W\left(\min \left\{(1+\gamma)\left(1-t_{P E}^{m}\right) y-\gamma y_{P}, y\right\}\right) .
\end{aligned}
$$

Note that if $(1+\gamma)\left(1-t_{P E}^{m}\right) y-\gamma y<0$, then the median voter is poor white, whereas the median voter is poor black if $(1+\gamma)\left(1-t_{P E}^{m}\right) y-\gamma y_{P}>y$. In the intermediate case, there will be two median voters that prefer the same tax, but generally have different incomes.

3. Poor whites identify as white. In this case poor blacks identify as black, so the taxes preferred by both blacks and whites are given by the decreasing function $t_{E}\left(y_{i}\right)$. The median tax $t_{E}^{m}$ is therefore defined implicitly by

$$
0.5=F\left((1+\gamma)\left(1-t_{E}^{m}\right) y-\gamma y\right)
$$

Since $F$ is increasing in its argument, (C6) and (C8) implies that

$$
(1+\gamma)\left(1-t_{E}^{m}\right) y-\gamma y=(1+\gamma)\left(1-t_{P}^{m}\right) y-\gamma y_{P}
$$

Rearranging this we see that

$$
t_{P}^{m}=t_{E}^{m}+\frac{\gamma\left(y-y_{P}\right)}{(1+\gamma) y}
$$

i.e., $t_{P}^{m}>t_{E}^{m}$.

In order to see that $t_{P E}^{m}$ is between these two tax rates, rewrite (C6) as

$$
0.5=p_{B} B\left((1+\gamma)\left(1-t_{P}^{m}\right) y-\gamma y_{P}\right)+\left(1-p_{B}\right) W\left((1+\gamma)\left(1-t_{P}^{m}\right) y-\gamma y_{P}\right)
$$

Using the relationship (C9) between $t_{E}^{m}$ and $t_{P}^{m}$ we can rewrite this as

$$
0.5=p_{B} B\left((1+\gamma)\left(1-t_{E}^{m}\right) y-\gamma y\right)+\left(1-p_{B}\right) W\left((1+\gamma)\left(1-t_{P}^{m}\right) y-\gamma y_{P}\right)
$$

Since the poor are in majority and all agents have positive incomes, it follows that $(\mathrm{C} 9)$ is positive, but less than $y$. We can therefore rewrite $(\mathrm{C} 10)$ as

$$
\begin{aligned}
0.5 & =p_{B} B\left(\max \left\{(1+\gamma)\left(1-t_{E}^{m}\right) y-\gamma y, 0\right\}\right) \\
& +\left(1-p_{B}\right) W\left(\min \left\{(1+\gamma)\left(1-t_{P}^{m}\right) y-\gamma y_{P}\right\}, y\right)
\end{aligned}
$$


Comparing this expression with $(\mathrm{C} 7)$ we can show that $t_{E}^{m}<t_{P E}^{m}<t_{P}^{m}$. First, suppose by contradiction that $t_{P E}^{m} \leq t_{E}^{m}$. Since $F$ is increasing in its argument, from (C11) it must be the case that

$$
\begin{aligned}
0.5 & <p_{B} B\left(\max \left\{(1+\gamma)\left(1-t_{P E}^{m}\right) y-\gamma y, 0\right\}\right) \\
& +\left(1-p_{B}\right) W\left(\min \left\{(1+\gamma)\left(1-t_{P E}^{m}\right) y-\gamma y_{P}\right\}, y\right),
\end{aligned}
$$

which implies that $(\mathrm{C} 7)$ cannot hold and we can conclude that $t_{P E}^{m}>t_{E}^{m}$. Similarly, suppose by contradiction that $t_{P E}^{m} \geq t_{P}^{m}$. Then again using $(\mathrm{C} 11)$ and the fact that $F$ is increasing implies that

$$
\begin{aligned}
0.5 & >p_{B} B\left(\max \left\{(1+\gamma)\left(1-t_{P E}^{m}\right) y-\gamma y, 0\right\}\right) \\
& +\left(1-p_{B}\right) W\left(\min \left\{(1+\gamma)\left(1-t_{P E}^{m}\right) y-\gamma y_{P}\right\}, y\right)
\end{aligned}
$$

which contradicts $(\mathrm{C} 7)$. We conclude that $t_{P}^{m}>t_{P E}^{m}>t_{E}^{m}$.

Now consider an increase in the proportion of blacks in the population. The only effect this will have is to make poor whites more likely to identify as white and poor blacks more likely to identify as poor. The result is therefore very similar to Proposition 3 . The only difference is that in the extended model there are three potential median tax rates. This implies that the tax rate may decrease as a result of poor whites switching to the white identity, which could not happen in the simple black and white model without interethnic income inequality (unless the poor whites are in majority).

Proposition C1 If blacks and whites have the same average income and proportion of poor, then an increase in the black population implies the following for the equilibrium tax rate:

1. If poor whites initially identify as white or both poor whites and poor blacks identify as poor, then the tax rate is unchanged.

2. If poor whites initially identify as poor and poor blacks identify as black, then poor blacks might switch to the poor identity resulting in a higher equilibrium tax rate or poor whites might switch to the white identity resulting in a lower equilibrium tax rate.

Proof. From Lemma C1 we know that there are three possible tax rates satisfying $t_{E}^{m}<t_{P E}^{m}<t_{P}^{m}$. As $p_{B}$ increases, the incomes of both groups are constant and it will only affect cognitive distances. From (C4) and (C5) it is clear that blacks will feel closer to 
the poor identity, whereas whites feel more distant to the poor identity. Recall that poor blacks identify as black if poor whites identify as white.

If poor whites initially identify as white (and consequently poor blacks as black), then the prevailing tax rate is $t_{E}^{m}$. An increase in $p_{B}$ cannot induce poor whites to switch identity, and consequently, poor blacks cannot switch to the poor identity. If both poor blacks and poor whites initially identify as poor, the tax rate is $t_{P}^{m}$ and an increase in $p_{B}$ cannot induce poor blacks to switch identity, which implies that poor whites will not change identity either. Finally, if poor whites initially identify as poor and poor blacks as black, then the initial tax rate is $t_{P E}^{m}$. In this case either poor blacks or poor whites might change identity (but not both), leading to the tax rate $t_{E}^{m}$ or $t_{P}^{m}$.

In the extended model, it becomes considerably more complicated to analyze the case when blacks are on average poorer than whites (as in Proposition B1, B2 and B3). The assumption that blacks and whites have the same average income and the same number of poor simplifies the analysis in three different ways. First, it implies that there are three instead of eight different combinations of identity choices. Second, there are maximally two rather than three median voters for given identity choices. Finally, it implies that we need not consider the two different cases depending on whether poor blacks prefer higher or lower taxes when they identify as black rather than poor. 


\section{References}

[1] Akerlof, G. A. and Kranton, R. E. (2000), 'Economics and Identity', Quarterly Journal of Economics 115(3), 715-753.

[2] Alesina, A. and Angeletos, G.-M. (2005), 'Fairness and Redistribution', American Economic Review 95(4), 960-980.

[3] Alesina, A., Baqir, R. and Easterly, W. (1999), 'Public Goods and Ethnic Divisions', Quarterly Journal of Economics 115(4), 1167-1199.

[4] Alesina, A., Glaeser, E. and Sacerdote, B. (2001), 'Why Doesn't the United States Have a European-Style Welfare State?', Brookings Paper on Economics Activity 2001(2), 187-254.

[5] Alesina, A. and La Ferrara, E. (2005a), 'Ethnic Diversity and Economic Performance', Journal of Economic Literature 43(3), 721-761.

[6] Alesina, A. and La Ferrara, E. (2005b), 'Preferences for Redistribution in the Land of Opportunities', Journal of Public Economics 89(5-6), 897-931.

[7] Austen-Smith, D. and Wallerstein, M. (2006), 'Redistribution and Affirmative Action', Journal of Public Economics 90(10-11), 1789-1823.

[8] Bénabou, R. and Tirole, J. (2006), 'Belief in a Just World and Redistributive Politics', Quarterly Journal of Economics 121(2), 699-746.

[9] Bernhard, H., Fischbacher, U. and Fehr, E. (2006), 'Parochial Altruism in Humans', Nature 442(7105), 912-915.

[10] Betz, H.-G. (1993), 'The New Politics of Resentment: Radical Right-Wing Populist Parties in Western Europe', Comparative Politics 25(4), 413-427.

[11] Bisin, A., Patacchini, E., Verdier, T. and Zenou, Y. (2006), 'Bend It Like Beckham': Identity, Socialization and Assimilation', CEPR Discussion Paper No. 5662. 
[12] Charness, G., Rigotti, L. and Rustichini, A. (2007), 'Individual Behavior and Group Membership', American Economic Review 97(4), 1340-1352.

[13] Chen, Y. and Li, S. X. (2009), 'Group Identity and Social Preferences', American Economic Review, forthcoming.

[14] Conde-Ruiz, J. I. and Galasso, V. (2003), 'Early Retirement', Review of Economic Dynamics 6(1), 12-36.

[15] Corneo, G. and Grüner, H. P. (2000), 'Social Limits to Redistribution', American Economic Review 90(6), 1491-1507.

[16] Davis, J. A., Smith, T. W. and Marsden, P. V. (2005), General Social Surveys 19722004, ICPSR04295-v1, 2005-09-02, Inter-university Consortium for Political and Social Research, Ann Arbor, MI.

[17] Dincer, O. and Lambert, P. J. (2006), 'Taking care of your own: Ethnic and religious heterogeneity and income inequality', University of Oregon Economics Department Working Paper.

[18] Efferson, C., Lalive, R. and Fehr, E. (2008), 'The Coevolution of Cultural Groups and Ingroup Favoritism', Science 321(5897), 1844-1849.

[19] Fernández, R. and Levy, G. (2008), 'Diversity and Redistribution', Journal of Public Economics 92(5-6), 925-943.

[20] Fong, C. (2001), 'Social Preferences, Self-Interest, and the Demand for Redistribution', Journal of Public Economics 82(2), 225-246.

[21] Fryer, R. G. and Torelli, P. (2006), 'An Empirical Analysis of 'Acting White", Mimeo, Harvard University.

[22] Gilens, M. (1999), Why Americans Hate Welfare: Race, Media, and the Politics of Antipoverty Policy, University of Chicago Press, Chicago. 
[23] Glazer, N. and Moynihan, D. P. (1970), Beyond the Melting Pot: The Negroes, Puerto Ricans, Jews, Italians, and Irish of New York City, 2 edn, MIT Press, Boston.

[24] Goette, L., Huffman, D. and Meier, S. (2006), 'The Impact of Group Membership on Cooperation and Norm Enforcement: Evidence Using Random Assignment to Real Social Groups', American Economic Review Papers and Proceedings 96(2), 212-216.

[25] Golder, M. (2003), 'Explaining Variation in the Success of Extreme Right Parties in Western Europe', Comparative Political Studies 36(4), 432-466.

[26] Habyarimana, J., Humphreys, M., Posner, D. N. and Weinstein, J. (2007), 'Why Does Ethnic Diversity Undermine Public Goods Provision? An Experimental Approach', American Political Science Review 101(4), 709-725.

[27] Kasher, A. and Rubinstein, A. (1997), 'On the Question ,"Who is a J?": A Social Choice Approach', Logique et Analyse 160, 385-395.

[28] Klor, E. F. and Shayo, M. (2009), 'Social Identity and Preferences Over Redistribution', Mimeo, Hebrew University.

[29] Knigge, P. (1998), 'The Ecological Correlates of Right-wing Extremism in Western Europe', European Journal of Political Research 34(2), 249-279.

[30] Lee, W. and Roemer, J. (2006), 'Racism and Redistribution in the United States: A Solution to the Problem of American Exceptionalism', Journal of Public Economics 90(6-7), 1027-1052.

[31] Levy, G. (2004), 'A Model of Political Parties', Journal of Economic Theory 115(2), $250-277$.

[32] Lind, J. T. (2005), 'Why is There So Little Redistribution?', Nordic Journal of Political Economy 31, 111-125.

[33] Lind, J. T. (2007), 'Fractionalization and the Size of Government', Journal of Public Economics $91,51-76$. 
[34] Lindqvist, E. (2007), Essays on Privatization, Identity and Political Polarization, Ph.D. Thesis, Stockholm School of Economics.

[35] Lipset, S. and Marks, G. (2000), It didn't happen here: Why socialism failed in the United States, W. W. Norton \& Co, New York.

[36] Loury, G. (2002), The Anatomy of Racial Inequality, Harvard University Press, Cambridge.

[37] Luttmer, E. F. P. (2001), 'Group Loyalty and the Taste for Redistribution', Journal of Political Economy 109(3), 500-528.

[38] Mas-Colell, A., Whinston, M. D. and Green, J. R. (1995), Microeconomic Theory, Oxford University Press, New York.

[39] McGann, A. J. and Kitschelt, H. (2005), 'The Radical Right in the Alps', Party Politics 11(2), 147-171.

[40] Meltzer, A. H. M. and Richard, S. F. (1981), 'A Rational Theory of the Size of Govern ment', Journal of Political Economy 89(5), 914-927.

[41] Myrdal, G. (1944), An American Dilemma. The Negro Problem and Modern Democracy, Harper \& Brothers Publishers, New York and London.

[42] Nieuwbeerta, P. and Ultee, W. (1999), 'Class Voting in Western Industrialized Countries, 1945-1990: Systematizing and Testing Explanations', European Journal of Political Research 35, 123-160.

[43] Orr, L. L. (1976), 'Income Transfers as a Public Good: An Application to AFDC', American Economic Review 66(3), 359-371.

[44] Östling, R. (2008), Bounded Rationality and Endogenous Preferences, Ph.D. Thesis, Stockholm School of Economics. 
[45] Penn, E. M. (2008), 'Citizenship versus Ethnicity: The Role of Institutions in Shaping Identity Choice', Journal of Politics 70(4), 956-973.

[46] Perotti, R. (1996), 'Growth, Income Distribution and Democracy: What the Data Say', Journal of Economic Growth 1(2), 149-187.

[47] Piketty, T. (1995), 'Social Mobility and Redistributive Politics', Quarterly Journal of Economics 110(3), 551-584.

[48] Poglia Mileti, F., Tondolo, R., Plomb, F., Schultheis, F., Meyer, M.-H., Hentges, G., Flecker, J. and Mairhuber, I. (2002), 'Modern Sirens and their Populist Songs: A European Literature Review on Changes in Working Life and the Rise of Right-wing Populism', Report from the SIREN project [http://www.siren.at].

[49] Posner, D. N. (2005), Institutions and Ethnic Politics in Africa, Cambridge University Press, New York.

[50] Roccas, S. (2003), 'The Effects of Status on Identification with Multiple Groups', European Journal of Social Psychology 33, 351-366.

[51] Roemer, J. (1998), 'Why the Poor Do Not Expropriate the Rich: An Old Argument in New Garb', Journal of Public Economics 70, 399-424.

[52] Roemer, J. and van der Straeten, K. (2005), 'Xenophobia and Distribution in France: A Politico-Economic Analysis', Journal of Economics 86, 95-144.

[53] Roemer, J. and van der Straeten, K. (2006), 'The Political Economy of Xenophobia and Distribution: The Case of Denmark', Scandinavian Journal of Economics 108, $251-277$.

[54] Scheve, K. F. and Slaughter, M. J. (2001), 'Labor Market Competition and Individual Preferences over Immigration Policy', Review of Economics and Statistics 83(1), 133145 . 
[55] Shayo, M. (2009), 'A Model of Social Identity with an Application to Political Economy: National, Class and Redistribution', American Political Science Review 103(2), $147-174$.

[56] Soss, J., Schram, S., Vartanian, T. and O'Brien, E. (2001), 'Setting the Terms of Relief: Political Explanations for State Policy Choices in the Devolution Revolution', American Journal of Political Science 45(2), 378-395.

[57] Spiegel (2005), 'It's Stupid to Be Afraid', Spiegel Special International Edition 2005(7), $21-23$.

[58] Turner, J., Hogg, M., Oakes, P, Reicher, S. and Wetherell, M. (1987), Rediscovering the Social Group: A Self-Categorization Theory, Basil Blackwell, Oxford.

[59] Waldman, B. (1987), 'Mechanisms of Kin Recognition', Journal of Theoretical Biology $128,159-185$. 